\title{
Crop Quality Improvement Through Genome Editing Strategy
}

\author{
Yihao Yang ${ }^{1,2,3}$, Chenda $\mathrm{Xu}^{1,2}$, Ziyan Shen ${ }^{1,2}$ and Changjie Yan ${ }^{1,2,3 *}$ \\ ${ }^{1}$ Jiangsu Key Laboratory of Crop Genetics and Physiology/Key Laboratory of Plant Functional Genomics of the Ministry of \\ Education/Jiangsu Key Laboratory of Crop Genomics and Molecular Breeding, Yangzhou, China, ${ }^{2}$ Jiangsu Co-Innovation Center \\ for Modern Production Technology of Grain Crops, Yangzhou, China, ${ }^{3}$ Department of Crop Genetics and Breeding, Agricultural \\ College of Yangzhou University, Yangzhou, China
}

OPEN ACCESS

Edited by:

Bing Yang,

University of Missouri, United States

Reviewed by:

Yanpeng Wang,

Institute of Genetics and

Developmental Biology (CAS), China

Kejian Wang,

China National Rice Research Institute

(CAAS), China

${ }^{*}$ Correspondence:

Changjie Yan

cjyan@yzu.edu.cn

Specialty section: This article was submitted to Genome Editing in Plants, a section of the journal

Frontiers in Genome Editing

Received: 22 November 2021

Accepted: 30 December 2021

Published: 31 January 2022

Citation:

Yang Y, Xu C, Shen Z and Yan C (2022) Crop Quality Improvement Through

Genome Editing Strategy.

Front. Genome Ed. 3:819687.

doi: 10.3389/fgeed.2021.819687
Good quality of crops has always been the most concerning aspect for breeders and consumers. However, crop quality is a complex trait affected by both the genetic systems and environmental factors, thus, it is difficult to improve through traditional breeding strategies. Recently, the CRISPR/Cas9 genome editing system, enabling efficiently targeted modification, has revolutionized the field of quality improvement in most crops. In this review, we briefly review the various genome editing ability of the CRISPR/Cas9 system, such as gene knockout, knock-in or replacement, base editing, prime editing, and gene expression regulation. In addition, we highlight the advances in crop quality improvement applying the CRISPR/Cas9 system in four main aspects: macronutrients, micronutrients, anti-nutritional factors and others. Finally, the potential challenges and future perspectives of genome editing in crop quality improvement is also discussed.

Keywords: crop, quality, improvement, gene editing, CRISPR/Cas9

\section{INTRODUCTION}

Quality is the most important economic character of crops, determining products' application value and market competitiveness. With the continuous improvement of people's living standards, higher requirements are put forward for crop quality. Cultivating more nutritious, more delicious and healthier crop varieties is of great significance to improving people's living standards and the sustainable development of social health. However, the pace of crop quality improvement has been relatively slow in the world due to the over-emphasis on demand for crop yield. The authors think that three main reasons are hindering the pace of crop quality improvement:1) The genetic control network of quality traits is extremely complex, and the available gene resources are still not abundant; 2) Crop quality traits are susceptible to environmental factors, such as fertilizer, climate and biological stress; 3 ) Traditional breeding methods (cross-breeding, mutation breeding and transgenic breeding) are time-consuming, random and introduce foreign genes.

A new generation of genome editing techniques, represented by regularly clustered interspaced short palindromic repeats/CRISPR-associated endonuclease 9 (CRISPR/Cas 9), is a revolutionary technology developed in the field of life sciences in recent years, which can produce predictable and heritable changes in specific locations of plant genomes. It includes deletion, insertion and replacement of base sequences to achieve precise improvement of plant traits. At the same time, compared with the traditional transgenic technology, the insertion site of the CRISPR/Cas9 expression vector is different from that of the gene-editing site. After the endogenous gene editing, the exogenous inserted plasmid can be removed by separating chromosomes during the generation of offspring gametes, thus eliminating the need to introduce exogenous genes. There is no 
transgenic controversy, and the application prospect is very broad. Providing a new turning point for the agricultural technology revolution.

At present, there are more and more cases of crop quality improvement using the CRISPR/Cas9 system. Here, we briefly review the various genome editing ability of the CRISPR/Cas9 system, summarized the recent progress in CRISPR/Cas9mediated crop quality improvement, and further discussed potential challenges and future perspectives of genome editing in crop quality improvement.

\section{ESTABLISHMENT OF THE CRISPR/CAS9 SYSTEM}

The CRISPR/Cas system is widely present in bacterial and archaebacterial genomes and is part of the adaptive immune system of microorganisms (Mojica et al., 2005; Grissa et al., 2007; Jinek et al., 2012). It consists of two core components: the clustered regularly interspaced short palindromic repeats (CRISPR) and Cas protein. The CRISPR constitutes 20-50 bp palindromic repeat sequence (Repeat), non-repeating 20-58 bp spacer sequence (Spacer) and AT-rich leading sequences (Leader). Cas protein acting as DNA endonuclease helps bacteria acquire new space sequences, essential for the bacterial immune system. According to the number and function of Cas proteins, CRISPR/Cas system has been divided into two classes and five types (I-V) (Makarova et al., 2011; Makarova and Koonin, 2015). Type I, III and IV belong to class I requiring multiple Cas proteins to form complex to work cooperatively. At the same time, type II and V belongs to class II interfering with target genes using only one single Cas protein. The immune process of the CRISPR/Cas system can be divided into three stages in bacteria (Makarova et al., 2011): 1) When foreign DNA infects bacteria, short DNA homologous fragments from protospacer sequences on bacteriophages or plasmids are integrated into the downstream of CRISPR leading sequence to form new space sequences; 2) CRISPR is induced to be transcribed into long RNA precursors (pre-crRNA), which are then truncated into short mature crRNAs, then the crRNAs precisely bind to trans-activating RNAs (tracrRNA) to fuses into tracrRNA/crRNA complexes; 3) The complexes regulate and guide Cas protein to precisely destroy the foreign DNA sequence, and produce DNA double-strand breaks (DSBs).

With a better understanding of the bacterial CRISPR/Cas immune system and its operational principle, scientists began to modify and apply this system to plant and animal genome editing (Cho et al., 2013; Cong et al., 2013; Feng et al., 2013; Mali et al., 2013; Ma et al., 2015; Yin et al., 2017). CRISPR/Cas9 system is the only class II type system reported for gene editing (Hsu et al., 2014). By artificial design, the tracrRNA/crRNA complex was simplified to a short guide RNA (sgRNA), which contains a $\sim 20 \mathrm{nt}$ fragment complemented to a specific site of target genes and followed by a protospacer adjacent motif (PAM) in the target genes of interest. Under the guidance of sgRNA, DSBs are created by Cas9 nuclease at $\sim 3$ bp upstream of the PAM motif and then repaired through the error-prone non-homologous end-joining
(NHEJ) or the error-free homology-directed repair (HDR) pathways. The NHEJ repaired way usually results in gene knockout to lose protein function (Liu et al., 2019). Alternatively, the HDR pathway can be triggered when an exogenous DNA repair template is provided, resulting in the introduction of the repair template into a target genomic region (Chapman et al., 2012).

\section{CRISPR/CAS9 SYSTEM IN PLANT FUNCTIONAL GENOMICS RESEARCH}

At present, the applications of the CRISPR/Cas9 system in plant genome editing mainly focus on gene function research and genetic improvement of crops. It has shown various genomeediting abilities, such as gene knockout, knock-in or replacement, base editing, prime editing, and expression regulation (Figure 1).

\subsection{Gene Knockout}

Gene knockout is the most extensive application of the CRISPR/ Cas9 system in plant functional genome research, which can be divided into single and multiplex gene knockout (Figure 1A). Under the guidance of sgRNA, the Cas9 nuclease cleaves the target DNA segment in the exon region of the gene to cause DSBs. The preferred NHEJ repair pathway is prone to produce insertions/deletions of one or several bases near the cutting site (Feng et al., 2014; Ma et al., 2015). When the number of inserted or missing bases is not multiple 3, the frameshift mutation will occur, and the target protein cannot be correctly encoded. It is worth noting that small insertions or deletions in edited cell lines may produce abnormal transcripts or proteins, causing unexpected effects that complicate functional analysis (Tuladhar et al., 2019). Therefore, many studies tend to produce two DSBs within a distance to delete larger genomic fragments to make true null alleles of coding and non-coding genes by NHEJ or microhomology-mediated end joining (MMEJ) repair (Owens et al., 2019; Tan et al., 2020).

Based on the high efficiency of CRISPR/Cas9 system-mediated gene knockout, multiplex gene knockout technology provided great convenience for functional analyzing the gene families, elucidating the regulation of multiple genes for complex agronomic traits, and analyzing the signal pathway in plants. Multiple sgRNAs with different targets for different genes can be designed and assembled into an expression cassette for transformation (Figure 1A). For example, our group constructed a CRISPR/Cas9 vector for targeting eight agronomic genes simultaneously based on the isocaudamerbased method. All editing genes have high mutation efficiencies in the $\mathrm{T}_{0}$ generation, and both heterozygous and homozygous genotypes at eight genes were obtained (Wang et al., 2015; Shen et al., 2017). In wheat, using the polycistronic tRNA strategy, Xia's group established an efficient CRISPR-Cas9 multiplex system which can edit multiplex genes simultaneously. They succeeded in targeting mutagenesis at up to 15 genomic loci, restoring transgenic free plants and pyramiding favorable alleles in an elite wheat variety within 1 year (Luo et al., 2021). In the case of homologous genes 


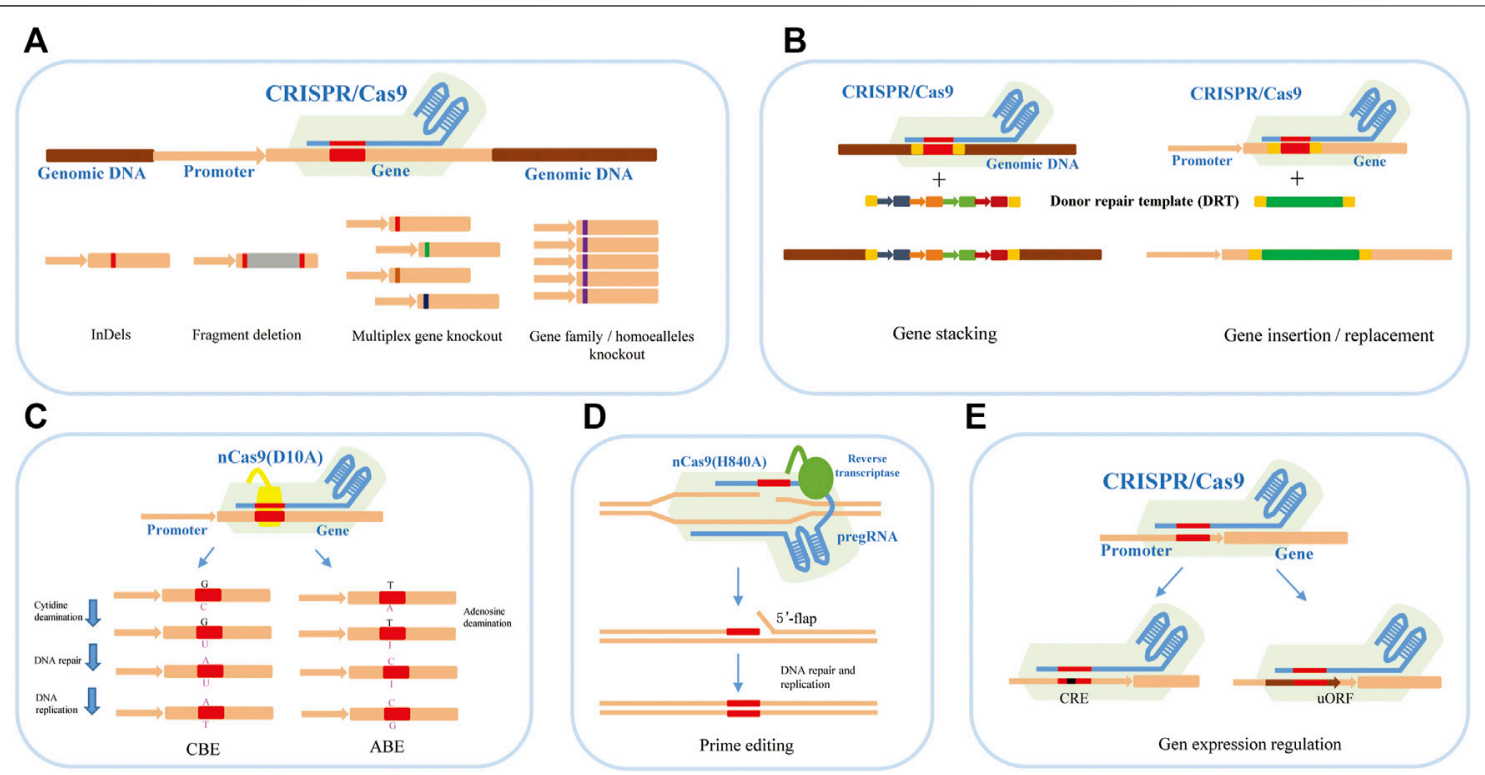

FIGURE 1 | The applications of the CRISPR/Cas9 system in plant genome editing. (A) CRISPR/Cas9-mediated gene knockout can achieve InDels, fragment deletion, and multiplex gene knockout. (B) CRISPR/Cas9-mediated gene knock-in and replacement mediated by HDR can achieve gene stacking and gene insertion or replacement to produce new traits in breeding. (C) CRISPR/Cas9-mediated base editing for crop trait improvement including CBE-mediated C-to-T base-editing strategy and ABE-mediated A-to-G base-editing strategy. (D) CRISPR/Cas9-mediated prime editing for crop trait improvement. (E) CRISPR/Cas9-mediated gene expression regulation by editing the cis-regulatory elements and upstream open reading frames (UORFs).

or gene families, one sgRNA targeting the conserved sequence can also achieve good results (Li A. et al., 2018; Sánchez-León et al., 2018).

\subsection{Gene Knock-In or Replacement}

During plant domestication, some alleles are consistent and fixed within elite germplasm, such as the wheat $Q$ allele (Zhang et al., 2011), rice $q S H 1$ (Konishi et al., 2006), maize teosinte branched 1 (Doebley, 2004) and tomato fw2.2 (Frary et al., 2000). Importantly, there are still many beneficial and favourable alleles in some local germplasm or related species. The replacement of endogenous genes or DNA fragments by the HDR pathway plays a useful role in crop breeding and trait improvement. HDR-mediated editing is a powerful genomeprecise editing tool that enables targeted gene replacement and direct introduction of elite alleles from local or related species into commercial varieties within a few generations without any linkage drag (Figure 1B). At present, precise knock-in or replacement of gene fragments has been achieved in many plants (Svitashev et al., 2015; Luo et al., 2016; Sun et al., 2016; Begemann et al., 2017; Shi et al., 2017; Wang et al., 2017; Li J. et al., 2018; Li S. et al., 2018; Hummel et al., 2018; Li et al., 2019). However, the genes of previous reported HDR cases are often resistant genes, which rely on selection pressure, or visible makers to enrich the HDR events. The editing efficiency is very low. There are four main challenges in performing HDR in plants: 1) HDR is in constant competition with NHEJ for the repair of DSBs, but the latter is the main pathway of DSB repair (Puchta 2005; Fauser et al., 2014; Shi et al., 2017; Fan et al., 2021); 2) HDR is only active during the late $\mathrm{S}$ and G2 phases, while the NHEJ is active during the overall cell cycle except for mitosis (Heyer et al., 2010; Karanam et al., 2012; Truong et al., 2013; Orthwein et al., 2014); 3) The donor repair template (DRT) is limited to deliver into the nucleus/cells for HDR; 4) The timing of DSBs induction and DRT transmission in target genes is difficult to coordinate (Gil-Humanes et al., 2017; Wang et al., 2017; Li and Xia, 2020).

To make editing more efficient, various strategies have been attempted in plants. There are mainly the following aspects: 1) Increasing the amount of DRT by using the bombardment deliver method or geminivirus replicons (GVR) (Baltes et al., 2014; Svitashev et al., 2015; Sun et al., 2016; Dong et al., 2020); 2) Improving the Cas9 frequency by using the specific promotors, such as egg cell- or early embryo-specific gene promoter; 3 ) Coordinating the delivery of Cas protein, two single-guide RNAs (sgRNAs) and DRT by using the all-in-one vector which includes all components (Peng et al., 2019). Despite these efforts, further improving HDR frequency and delivering sufficient DRT into plant cells remains very challenging.

\subsection{Base Editing}

Single-nucleotide point (SNP) mutations are the genetic basis for sharping phenotypic diversity among individuals. Base editing refers to the transformation of a single base at a specific position in a target DNA fragment. This technology does not depend on the generation of DNA DSBs so as to avoid both the randomness of NHEJ and the low efficiency of HDR. Base editors are created by fusing an engineered base modification enzyme, such as deaminase, with the catalytically dead version of the Streptococcus pyogenes Cas9 (dCas9) or nickase version of Cas9 (nCas9) (D10A) and currently include cytosine base 
editors (CBEs) and adenine base editors (ABEs) (Figure 1C). $\mathrm{CBEs}$ use a naturally occurring cytidine deaminase to convert target cytosines to uracil, which catalyzes $\mathrm{C} \bullet \mathrm{G}$ to $\mathrm{T} \bullet \mathrm{A}$ conversion (Komor et al., 2016). Drawing inspiration from CBEs, adenosine deaminase would result in inosine, which is read as guanine by replication and transcription machinery. Therefore, ABEs would correct $\mathrm{A} \bullet \mathrm{T}$ to $\mathrm{G} \bullet \mathrm{C}$ mutation theoretically (Gaudelli et al., 2017). The establishment of CBEs and ABEs system enables single base editing to realize four types of base conversion and has been successfully used in crop plants (Bharat et al., 2020). Recently, some progress has been made in the study of crop gene-directed evolution using base editing technology. For example, Li et al. (2020b) developed saturated targeted endogenous mutagenesis editors (STEMES) fusing cytidine deaminase with adenosine deaminase to achieve $\mathrm{C}: \mathrm{G}>\mathrm{T}$ : $\mathrm{A}$ and $\mathrm{A}: \mathrm{T}>\mathrm{G}: \mathrm{C}$ substitutions simultaneously, which facilitate directed evolution of plant genes by generating de novo mutations. A series of highly efficient BE toolkits were developed to achieve C-to-T mutation almost without PAM restriction, and the A-to-G mutation scope was largely expanded in rice (Zhang et al., 2021). Kuang et al. (2020) presented a base-editor-mediated gene evolution method (BEMGE), which is a powerful tool that can accurately identify functional genetic variations and develop specific traits in crop breeding programs soon.

\subsection{Prime Editing}

Although the base editing technique has been able to achieve precise $\mathrm{C} \bullet \mathrm{G}-\mathrm{T} \bullet \mathrm{A}$ and $\mathrm{A} \bullet \mathrm{T}-\mathrm{G} \bullet \mathrm{C}$ base conversion, it is difficult to achieve precise transversion between pyrimidine and purine bases and precise insertion or deletion of small fragments. In 2019, David R. Liu's lab developed a revolutionary new tool for precise gene editing, the prime editor (PE), which is a search-andreplace genome-editing method and has realized all 12 kinds of base substitutions, precise insertions of up to $44 \mathrm{bp}$, deletions of up to $80 \mathrm{bp}$ and combinations of these edits in human cells (Anzalone et al., 2019). PE is composed of three components: nCas9(H840A), reverse transcriptase (RT), and prime editing guide RNA (pegRNA). Compared with sgRNA of CRISPR/Cas9 system, pegRNA has an additional RNA sequence at the $3^{\prime}$ end, including prime binding site (PBS) that pairs with the nCas9 (H840A)-nicked ssDNA strand sequence and initiates RT, and reverse transcriptase template (RT template) that contains the genetic information for the desired mutations. Under the guidance of pegRNA, nCas9(H840A) cleaves and releases the non-target DNA strand to hybridize to the PBS in the pegRNA. Reverse transcriptase synthesizes new DNA using the RT template, and the newly synthesized DNA containing the target editing is introduced into the genome to replace the original DNA sequence through DNA repair (Figure 1D). At present, this technology has been established and optimized in plants (Lin et al., 2020). However, the editing efficiency of PE is very low and varies greatly at different loci, which cannot meet the needs of basic research and practical application (Li J. et al., 2020; Gao et al., 2021). Scientists have optimized it from different angles to improve the editing efficiency of PE in plants. For example, Lin et al. (2020) optimized prime editors for plants through codon, promoter, and editing-condition optimization.
They successfully obtained the regenerated prime-edited rice plants at frequencies of up to $21.8 \%$. Lin et al. (2021) evaluated the melting temperature of PBS and showed that $30^{\circ} \mathrm{C}$ leads to maximal efficiency. They also presented a dualpegRNA approach, which uses two pegRNAs in trans encoding the same edits, substantially enhances PE efficiency. A web application called PlantPegDesigner was provided to simplify the design of optimal pegRNAs or pegRNA pairs.

\subsection{Expression Regulation}

Although the most frequent application of CRISPR/Cas9 is to create null alleles by targeting the coding sequences, loss-offunction mutations in coding regions may result in pleiotropic or deleterious effects ( $\mathrm{Li}$ et al., 2020a; Hendelman et al., 2021). Numerous researches in both animals and plants have revealed that many genetic changes driving evolution, domestication, and breeding occurred in cis-regulatory regions, including upstream, introns, and downstream regions of genes (Wang et al., 2014; Ding et al., 2021). Compared with coding region mutations, cis-regulated region editing is more likely to induce small phenotypic changes by modifying the level, timing, or space of gene expression, which benefit crop improvement.

To date, the alteration of gene expression in plants genome editing has focused mainly on editing or directly deleting the cisregulatory elements (CRE) in the promoter region of the target genes (Figure 1E). For example, Rodríguez-Leal et al. (2017) edited the promoters of genes that control fruit size, inflorescence branching, and plant architecture by using a multiplexed CRISPR/Cas9 promoter targeting approach. This approach obtained the artificial QTL variation and precisely regulated fruit size and other important agronomic traits in tomatoes. Hendelman et al. (2021) used a cis-regulatory editing system to generate a comprehensive allelic series for tomato WUSCHEL HOMEOBOX9 (WOX9), which plays a species-specific role in embryo and inflorescence development. This research showed that tomato WOX9 has a pleiotropic function, which is regulated by cis-sequence elements at different locations of the gene promoter region. A similar strategy, Liu et al. (2021) achieved quantitative variation of maize yield-related traits by making weak promoter alleles of CLE genes associated with increased meristem size through CRISPR-based promoter fine-tuning.

In many cases, many genes that regulate important traits require a high rate of translation to achieve crop improvement, rather than loss or reduction of function (Xu et al., 2017; Reis et al., 2020). Upstream open reading frames (uORFs) are important cis-regulatory elements in the $5^{\prime}$ leading sequence of eukaryotic mRNAs, and usually inhibit the translation initiation of downstream ORFs through ribosome stalling (Zhang et al., 2020; Kurihara, 2020). Fine-tuning the translation by regulating uORFs can effectively improve the translation efficiency of target genes for the improvement of crop traits (Figure 1E). For example, editing the uORF of $L s G G P 2$ increased oxidative stress tolerance and the ascorbate content of lettuce by $\sim 150 \%$ (Zhang et al., 2018). In Arabidopsis thaliana, deleting the uORF of PHO1 increased shoot Pi content and improved shoot growth under low external Pi supply (Reis et al., 2020). 
TABLE 1 | List of research on crop quality improvement by using CRISPR/Cas9 system.

\begin{tabular}{|c|c|c|c|c|c|}
\hline Traits & Target traits & Crop & Target gene & $\begin{array}{l}\text { Type of } \\
\text { edit }\end{array}$ & References \\
\hline \multirow[t]{21}{*}{ Macronutrient improvement } & Starch & Rice & GBSSI & Gene knockout & $\begin{array}{l}\text { Ma et al. (2015) } \\
\text { Zhang et al. (2017) } \\
\text { Fei et al. (2019) }\end{array}$ \\
\hline & & & GBSSI & Expression regulation & $\begin{array}{l}\text { Huang L. et al. (2020) } \\
\text { Zeng et al. (2020b) }\end{array}$ \\
\hline & & & GBSSI & Base editing & $\begin{array}{l}\text { Li H. et al. (2020) } \\
\text { Xu Y. et al. (2021) }\end{array}$ \\
\hline & & Barley & GBSSI & Gene knockout & Zhong et al. (2018) \\
\hline & & Cassava & GBSSI & Gene knockout & Bull et al. (2018) \\
\hline & & Maize & GBSSI & Gene knockout & $\begin{array}{l}\text { Gao et al., 2020; } \\
\text { Dong et al. (2019) }\end{array}$ \\
\hline & & Rice & SBEIllb & Gene knockout & Sun et al. (2017) \\
\hline & & Wheat & SBElla & Gene knockout & Li et al. (2021) \\
\hline & Proteins & Barley & D-hordein & Gene knockout & Li Y. et al. (2020) \\
\hline & & Wheat & a-gliadin & Gene knockout & Sánchez-León et al. (2018) \\
\hline & & Sorghum & a-kafirins & Gene knockout & Li A. et al. (2018) \\
\hline & & Soybean & Gly $m$ Bd $28 \mathrm{~K}$ & Gene knockout & Sugano et al. (2020) \\
\hline & & & Gly $m$ Bd $30 \mathrm{~K}$ & & \\
\hline & & Rice & OsAAP6, OsAAP10 & Gene knockout & Wang et al. (2020) \\
\hline & Oils & Rapeseed & BnaA.FAD2.a & Gene knockout & Okuzaki et al. (2018) \\
\hline & & Rapeseed & BnaFAD2 & Gene knockout & Huang H. et al., 2020 \\
\hline & & Rapeseed & BnTा8 & Gene knockout & Zhai et al., 2020 \\
\hline & & Camelina & CsFAD2 & Gene knockout & Lee et al. (2021) \\
\hline & & Soybean & FAD2-1 & Gene knockout & Al Amin et al. (2019) \\
\hline & & Soybean & FAD2-2 & Gene knockout & Do et al. (2019) \\
\hline & & Rice & OsFAD2-1 & Gene knockout & Abe et al. (2018) \\
\hline \multirow[t]{9}{*}{ Micronutrient improvement } & Anthocyanins & Rice & $R c$ & Gene knockout & Zhu et al. (2019) \\
\hline & & Tomato & ANT1 & Gene knock-in & Čermak et al. (2015) \\
\hline & & Tomato & SIMYB12 & Gene knockout & $\begin{array}{l}\text { Deng et al., 2018; } \\
\text { Yang T. et al. (2019) }\end{array}$ \\
\hline & & Carrot & DCMYB7 & Gene knockout & Xu et al. (2019) \\
\hline & Vitamins & Rice & sSU-crtl, ZmPsy & Gene knock-in & Dong et al. (2020) \\
\hline & & Lettuce & LsGGP2 & Expression regulation & Zhang et al. (2018) \\
\hline & $\gamma$-aminobutyric acid & Tomato & SIGAD2, SIGAD3 & Gene knockout & Nonaka et al. (2017) \\
\hline & & Rice & GAD3 & Gene knockout & Akama et al. (2020) \\
\hline & & Tomato & $\begin{array}{l}\text { GABA-TP1, GABA-TP2, } \\
\text { GABA-TP3, CAT9, SSADH. }\end{array}$ & Gene knockout & Li R. et al. (2018) \\
\hline \multirow[t]{7}{*}{ Elimination of Anti-nutritional factors } & Phytic acid & Rice & OsPLD $\alpha 1$ & Gene knockout & Khan et al. (2019) \\
\hline & & Rapeseed & BnITPK & Gene knockout & Sashidhar et al. (2020) \\
\hline & Heavy metals & Rice & OsNramp5 & Gene knockout & Tang et al. (2017) \\
\hline & & Rice & OsHAK1 & Gene knockout & Nieves-Cordones et al. (2017) \\
\hline & Enzymatic browning & Potato & StPPO2 & Gene knockout & González et al. (2020) \\
\hline & Steroidal glycoalkaloids & Potato & St16DOX & Gene knockout & Nakayasu et al. (2018) \\
\hline & Acrylamide & Wheat & TaASN2 & Gene knockout & Raffan et al. (2021) \\
\hline \multirow[t]{10}{*}{ Other improvements } & Fragrant aromas & Rice & OsBADH2 & Gene knockout & $\begin{array}{l}\text { Ashokkumar et al. (2020); } \\
\text { Hui et al. (2021) }\end{array}$ \\
\hline & & Rice & OsBADH2 & Gene knockout & Tang et al. (2021) \\
\hline & & Maize & $B A D H 2$ & Gene knockout & Wang et al. (2021) \\
\hline & Shelf-life & Banana & MaACO1 & Gene knockout & Hu et al. (2021) \\
\hline & & Petunias & PhAC 1 & Gene knockout & Xu et al. (2019) \\
\hline & & Tomato & $R I N$ & Gene knockout & Ito et al. (2015) \\
\hline & & Tomato & Cnr & Gene knockout & Gao et al. (2019) \\
\hline & & Tomato & Nor & Gene knockout & Gao et al. (2019) \\
\hline & & Tomato & $A L C$ & Gene replacement & Yu et al. (2017) \\
\hline & & Tomato & $P L$ & Gene knockout & Wang D. et al. (2019) \\
\hline
\end{tabular}




\section{CRISPR/CAS9 SYSTEM FOR CROP QUALITY IMPROVEMENT}

A balanced, varied, and appropriate healthy diet ensures a person's needs for macronutrients and essential micronutrients. It protects against undernutrition, micronutrient deficiencies, and non-communicable diseases such as obesity, diabetes, heart disease, stroke, and cancer. This is the foundation of a good life. The edible part of crops is mainly composed of macronutrients (starch, protein and oil) and micronutrients (anthocyanins, vitamins, $\gamma$-aminobutyric acid etc.). In the past 5 years, scientists have used CRISPR/ Cas9 technology to study the nutritional components of crops and flavour and storage characteristics, and achieved great success (Table 1).

\subsection{Macronutrient Improvement}

\subsubsection{Starch}

Starch, a high molecular carbohydrate, is a major component of harvestable crop organs and a major energy source in the human diet and an industrial feedstock. It widely exists in maize (Zea Mays), rice (Oryza sativa), wheat (Triticum aestivum), barley (Hordeum vulgare), potato (Solanum tuberosum), cassava (Manihot Esculenta), and other starch crops. Starch consists of amylopectin and amylose and is stored as semi-crystalline granules in the chloroplasts of leaves and amyloplasts of storage organs. Amylopectin has a dendritic structure, which determines the crystallinity of starch granules. Amylose is a linear glucose polymer, accounting for only about $20 \%$ of the granules. Still, it strongly determines the physicochemical properties of starch, such as stickiness, palatability, and digestibility during cooking and processing (Jobling, 2004; Sonnewald and Kossmann, 2013; Emmambux and Taylor, 2016). At present, the genetic mechanism of starch has been well analyzed. With glucose-1-phosphoric acid (Glc-1-P) as raw material, ADPG is formed under the action of glucose pyrophosphorylase (AGPase). Amylose is synthesized under the action of grain binding starch synthase GBSSI; Amylopectin is synthesized by soluble starch synthase (SSS), branching enzyme (SBE) and debranching enzyme (DBE). At the molecular level, all the genes involved in starch synthesis and regulation can affect starch quality. Knocking out Wx (GBSSI) leads to the rapid reduction of amylose, amylopectin content up to nearly $100 \%$ in starch granules, referred to as waxy or glutinous starch. For example, Ma et al. (2015), Zhang et al. (2017) and Fei et al. (2019) successfully reduced the amylose content of the mutant to less than $5 \%$ by knocking out the exon region of rice waxy gene $W x$ to obtain waxy rice. The same knockout strategy is also used for barley and cassava (Bull et al., 2018; Zhong et al., 2018). Gao et al. (2020) created waxy corn hybrids by deleting large segments of a waxy allele using CRISPR-Cas9 in 12 elite inbred maize lines. Field trials at 25 locations showed that CRISPR-waxy hybrids were agronomically superior to introgressed hybrids. Specially, this CRISPR-Cas9 waxy corn is considered unregulated by the relevant regulations of APHIS and has been conducted a precommercial launch in the Midwestern United States in 2019. 'Sweet-waxy compound corn' is now widely favoured for its chewiness and sweetness. Dong et al. (2019) edited SH2 and $W x$ and identified single or double mutations that can be used to produce super-sweet, waxy or sweet and waxy compound corns (SWCs) that can be used in specialty corn breeding. In addition to occurring frameshift of $W x$, scientists are trying to fine-tune AC by manipulating $W x$ at expression, post-transcriptional, and translational levels. Rice $W x$ variants including $W x^{l v}, W x^{a}$, $W x^{b}, W x^{i n}, W x^{m w}, W x^{o p / h p}, W x^{m p}, W x^{m q}$, and $w x$ determine the eating and cooking quality (ECQ) of rice. Huang L. et al. (2020) generated six novel $W x$ alleles by editing the region near the TATA box of the $W x^{b}$ promoter, which downregulated $W x$ expression and fine-tuned grain AC. Zeng et al. (2020b) targeted the $5^{\prime}$ UTR intronic splicing site (5'UISS) of $W x^{a}$ to alter the intron-splicing efficiency and generate new quantitative trait alleles. Li et al. (2020c) and Xu Y. et al. (2021) used the CRISPR/Cas9-mediated base editing system to target regions closed to the mentioned 'soft rice' allele responsible sites for mild reduction of rice AC.

Foods with high amylose content and resistant starch (RS) contribute to improving human health and reducing the risk of serious noninfectious diseases, while cereal crops high in RS are not widely available (Zhu et al., 2012). Researches showed that the starch branching enzyme ( $S B E)$ gene controls amylopectin synthesis, and the contents of amylose and resistant starch (RS) would increase in SBE mutated crops (Shimada et al.,2006). Sun et al. (2017) conducted targeted mutagenesis of rice SBEIIb using CRISPR/Cas9 technology, and the AC and RS contents were significantly increased to 25.0 and $9.8 \%$, respectively. Li et al. (2021) also conducted directed mutagenesis of TaSBEIIa of winter wheat and spring wheat varieties through CRISPR/Cas9, and obtained transgenic highstraight wheat with improved starch composition, structure and properties.

\subsubsection{Proteins}

Plant seed storage proteins (SSPs) are important sources of human dietary protein, mainly from cereals and legumes. According to the solubility-linked physical properties, SSPs are classified as four fractions: water-soluble albumins, salt-soluble globulins, alcohol-soluble prolamins, and alkaline-soluble glutelins. The proportions of these four kinds of proteins in different crop seeds are different. For example, glutelin is the most abundant protein fraction in rice and comprises about $60-80 \%$ of the total SSPs, while prolamin is the dominant one in maize, wheat and barley (Yang Y. et al., 2019). Many studies have shown that the level and proportion of protein fraction content greatly impact crop quality. Manipulating seed storage protein content by CRISPR/Cas9 gene editing is an effective way to regulate seed nutritional value. In barley, $\mathrm{D}$ hordein is one of the storage proteins in the grain, which has a negative effect on malting quality. Li Y. et al. (2020) used CRISPR/Cas9 technology to edit the $D$ hordein gene in a spring barley cultivar and obtained two mutated lines. Transcriptomic analysis and protein SDS-PAGE showed that the transcription level of the D hordein gene and D hordein content in the mutant was lower than that of the wild type, which provided a basis for breeding high malt quality varieties. In wheat, the $a$-gliadin family is the main protein 
group associated with celiac disease. This genetic autoimmune disorder damages the small intestine and interferes with the absorption of nutrients from food. The gliadin contains a 33amino acid polypeptide, called 33-mer, the main immunodominant peptide in celiac patients. Sánchez-León et al. (2018) targeted a conserved region adjacent to the coding sequence for the 33-mer in the gliadin genes with two sgRNAs and obtained low gluten hexaploid and durum wheat, of which immunoreactivity was reduced by $85 \%$. A similar knockout strategy was carried out in sorghum. A single sgRNA was designed to mutate conserved region encoding the a-kafirins endoplasmic reticulum signal peptide. Edited plants' grain protein digestibility and lysine content significantly increased (Li A. et al., 2018). In soybean, many allergens have been identified, resulting in $5-8 \%$ of babies and $2 \%$ of adults being allergic to soybean in the United States and Europe (Heppell et al., 1987). Sugano et al. (2020) designed two sgRNAs simultaneously site-directed mutate two genes encoding the major allergens Gly $\mathrm{m} \mathrm{Bd} 28 \mathrm{~K}$ and Gly $\mathrm{m} \mathrm{Bd} 30 \mathrm{~K}$ in two Japanese soybean varieties and successfully obtained Cas9-free plants with no Gly $\mathrm{m} \mathrm{Bd}$ 28 Kor Gly $\mathrm{m} \mathrm{Bd} 30 \mathrm{~K}$ protein. In rice, grain storage protein seriously affects the quality of rice, especially the eating and cooking quality (ECQ) (Yang et al., 2015; Yang et al., 2020). Generally, the higher rice grain protein content (GPC) will lead to the worse ECQ; thus, the cultivars with good ECQ always are required to have relatively lower GPC, usually less than 7\%. Wang et al. (2020) used CRISPR/Cas9 system to knock out OsAAP6 and OsAAP10 in three high-yielding japonica varieties and one japonica line, respectively. The protein content of the mutants was decreased, and the ECQ was increased significantly.

\subsubsection{Oils}

Seed oils are primarily used as edible oils, and their industrial application has also been gradually increasing (Biermann et al., 2011). The most seed oil contains high content of polyunsaturated fatty acids (PUFAs) such as linoleic acid but low content of monounsaturated acids (MUFAs) such as oleic acid. Notably, PUFAs oil tends to oxidize, resulting in rancidity, off-flavours, and short shelf-life. In contrast, high MUFAs oil is 10 -fold higher auto-oxidizing stable than linoleic acid, which is not only beneficial for lowering cholesterol and reducing systolic blood pressure, but also preferred for industrial uses, for example as biodiesel duels and biolubricants (O'Keefe et al., 1993; Davis et al., 2008; Terés et al., 2008). Therefore, industry and food products prefer to use high-oleic vegetable oil, and many studies have begun to alter the fatty acid composition of oilseed crops artificially. Fatty acid desaturase 2 (FAD2) catalyzes the conversion of oleic acid to linoleic acid in plants, and many studies reported that suppressing FAD2 gene expression can develop the high-oleic oilseed crops (Okuley et al., 1994; Sivaraman et al., 2004; Jung et al., 2011; Nguyen et al., 2013; Chen et al., 2015; Lee et al., 2016; Lee et al., 2017; Wood et al., 2018). Recently, scientists have done a lot of work to improve the oil quality using CRISPR/Cas9 technology, mainly focusing on some oil crops, such as rapeseed, soybean, camelina, etc. Okuzaki et al. (2018) targeted the BnaA.FAD2.a (FAD2_Aa) in B. napus to increase the oleic acid content. Huang $H$. et al. (2020) designed two sgRNAs, one of which targets four copies of BnaFAD2. The oleic acid content in seeds of mutant increased significantly, with a maximum of more than $80 \%$ compared with wild type of $66.43 \%$, and with a decrease in linoleic and linolenic acid content. Compared with black-seeded rape, yellow-seeded $B$. napus has the characteristics of the thinner seed coat, low lignin and polyphenol content, high oil content and high protein content, so it is widely accepted as a good-quality trait. Zhai et al. (2020) targeted BnTT8, which controls flavonoid accumulation in crops, to successfully obtain yellow-seeded lines with elevated oil and protein content and altered fatty acid (FA) composition using the CRISPR/Cas9 system. In hexaploid Camelina sativa, Lee et al. (2021) used a single guide RNA covering the common region of the three CsFAD2 homologs. When all three homologous genes were knocked out, seed MUFA levels increased by nearly $80 \%$, but with a stunted bushy phenotype. However, transformants with two pairs of CsFAD2 homologs mutated but the other pair with wild-type heterozygous showed normal growth, and a seed MUFAs production increased up to $60 \%$. In soybean, Al Amin et al. (2019) and Do et al. (2019) respectively mutated FAD2-1 and FAD2-2 loci using the CRISPR/Cas9 system to increase the oleic acid content in edited soybean plants. Besides oil crops, rice bran oil (RBO) contains many valuable healthy constituents, including oleic acid. In rice, three functional FAD2 genes were found, and only OsFAD2-1 is the highest expressed in rice seeds. Abe et al. (2018) disrupted the OsFAD2-1 gene by CRISPR/Cas9 system, and the oleic acid content of homozygous knockout plants was increased to more than twice that of wild type.

\subsection{Micronutrient Improvement 4.2.1 Anthocyanins}

Anthocyanins are water-soluble flavonoid compounds widely distributed in plants and confer pigmentation to plants. They are all recognized antioxidants with human health benefits, such as reducing the risk of diabetes, obesity, cardiovascular disease (CVD), and certain cancers (Wang and Stoner 2008; Tsuda 2012; Vinayagam and Xu 2015; Wallace et al., 2016). Wild rice species (Oryza rufipogon L.)are rich in proanthocyanidins and anthocyanidins and show red pericarp, which is regulated by two complementary genes $R c$ and $R d$. $R c$ encodes a basic helixloop-helix (bHLH) transcription factor, and $R d$ encodes a dihydroflavonol-4-reductase (DFR) protein (Sweeney et al., 2006; Furukawa et al., 2007). At present, most cultivated rice varieties produce white grain due to the frameshift mutation in the exon of the $R c$ gene. Zhu et al. (2019) successfully reverted frameshift mutation into in-frame mutations by using CRISPR/ Cas9-mediated method, restoring the function of $R c$ allele and converting three elite white pericarp rice varieties into red ones with high content of proanthocyanidins and anthocyanidins. Čermák et al. (2015) inserted a 1938 bp donor template into the promoter region of tomato ANT1 gene controlling anthocyanin biosynthesis, resulting in overexpression and ectopic accumulation of pigments in tomato tissues. In addition, consumers in different regions have different fruit colour preferences; scientists also use CRISPR/Cas9 technology to regulate genes related to anthocyanin synthesis to achieve the 
effect of changing fruit colour. For example, European and the American consumers prefer red fruit tomatoes, while pink fruit tomatoes are more popular in Asian countries, especially in China and Japan (Lin et al., 2014). However, most tomato breeding materials are red fruit materials. Using the CRISPR/Cas9 system, Li's group accelerated the breeding process by disrupting the SlMYB12 gene, a key determinant for flavonoid accumulation, of a superior red tomato inbred line to produce tomato plants with pink fruit (Deng et al., 2018; Yang T. et al., 2019). Xu et al. (2019) knocked the DcMYB7, which activates the expression of its DcbHLH3 partner, a structural gene in the anthocyanin biosynthetic pathway, in a solid purple carrot using CRISPR/ Cas9 system resulted in carrots with yellow roots.

\subsubsection{Vitamins}

Vitamins are a small part of the organic compounds that are needed in the human diet. We have known that vitamin deficiency is directly linked to human disease. For example, vitamin A deficiency causes visual problems, such as night blindness and even blindness in severe deficiency. However, as rice lack provitamin A (mainly $\beta$-carotene), the poor populations in the developing countries of South and Southeast Asia, where white rice is a staple food, cannot meet vitamin A intake dependency criteria. Dong et al. (2020) inserted a $5.2 \mathrm{~Kb}$ carotenoid biosynthesis cassette consisting of the coding sequences of SSU-crtI and ZmPsy at two genomic safe harbors in rice using CRISPR-Cas9 technology and successfully obtained marker-free rice plants with high carotenoid content in seeds. Numerous epidemiological studies have shown a positive association between dietary or plasma levels of vitamin $\mathrm{C}$ content and health benefits. The major source of vitamin $C$ in the human diet is ascorbic acid (ASA) from fruit and vegetables. Zhang et al. (2018) targeted the uORF initiation codon region of LsGGP2, a key enzyme in vitamin C biosynthesis in lettuce, it not only increased the antioxidant stress ability of lettuce, but also increased ascorbate content by $\sim 150 \%$.

\subsection{3 $\gamma$-aminobutyric Acid (GABA)}

The $\gamma$-aminobutyric acid (GABA), a four-carbon nonprotein amino acid widely presenting in plants, functions as an inhibitory neurotransmitter in the central nervous system for animals to alleviate hypertension ((Bachtiar et al., 2015). In plants, GABA is first synthesized from its precursor glutamate by glutamate decarboxylase (GAD), and then catabolized to succinate by GABA transaminase (GABA-T) and succinic semialdehyde dehydrogenase (SSADH) in a subsequent reaction. Applying the CRISPR/Cas9 system to regulate the related genes in the GABA synthesis pathway can rapidly increase the GABA content plants and improve crops nutritional quality. Previous reports indicated that GAD has a C-terminal autoinhibitory domain that regulates enzymatic function, and deletion of this domain increases GAD activity. Nonaka et al. (2017) deleted the autoinhibitory domain of SlGAD2 and SlGAD3, expressed during tomato fruit development using the CRISPR/Cas9 system, and the premature termination before the autoinhibitory domain increased GABA accumulation by $7-15$ fold. Similarly, Akama et al. (2020) knocked the GAD3, which is predominantly expressed in rice seeds and obtained the edited lines with seven-fold higher levels of GABA. Li R. et al. (2018) manipulated the GABA shunt in tomatoes by targeting five key genes, namely GABA-TP1, GABA-TP2, GABA-TP3, CAT9 and SSADH. The accumulation of GABA in the leaves and fruits of the edited lines was significantly increased, and the GABA content in the leaves of quadruple mutants was 19-fold higher than that of wild type.

\subsection{Elimination of Anti-nutritional Factors}

Anti-nutritional factors (ANFs) refer to substances in the feed that adversely affect digestion, absorption and utilization of nutrients and cause adverse physiological reactions in humans and animals, such as phytic acid (PA) and heavy metal quinones, steroidal glycoalkaloids, and free asparagine. The use of geneediting techniques to eliminate the ANFs in crops edible parts could benefit human health.

\subsubsection{Phytic Acid}

PA acts as a major reservoir of phosphorus in seeds from cereals to oilseeds but strongly chelates essential minerals in human and monogastric animals, leading to so-called "hidden hunger." The lipid-dependent and lipid-independent pathways are two known phytic acid biosynthesis pathways (Bhati et al., 2014; Kuo et al., 2018). The lipid-dependent pathway involves the inositol lipid phosphatidylinositol (PI), which produces phytic acid through a continuous reaction processes. Khan et al. (2019) used the CRISPR/Cas9 system to generate mutants of a phospholipase D gene $(O s P L D \alpha 1)$ to disrupt the production of phosphatidic acid and reduce the phytic acid in rice seeds. Compared with the wild type, the expression of key genes related to phytic acid biosynthesis was changed and the phytic acid content was significantly reduced in ospld 1 mutants. In Brassica napus. L., the key enzyme ITPK (inositol tetrakisphosphate kinase) catalyzes the penultimate step for synthesising PA in the lipidindependent pathways (Raboy, 2009). Knocking out three functional paralogs of BnITPK resulted in low PA and high free phosphorus using CRISPR-Cas9 system (Sashidhar et al., 2020).

\subsubsection{Heavy Metals}

Heavy metals, which can be taken up by crops and transported to their edible parts, is widely known to be harmful to health. Cadmium (Cd) is a highly toxic heavy metal that causes osteoporosis, kidney failure, cancer, and cardiovascular diseases for humans (Bertin and Averbeck, 2006). Rice with excessive cadmium is the main source of dietary cadmium intake. Previous researches reported that the natural resistance-associated macrophage proteins 5 (NRAMP5) mediate the root uptake of Cd (Ishikawa et al., 2012; Sasaki et al., 2012). Tang et al. (2017) designed two sequence-specific single guide RNA (sgRNA) to target exon IX of OsNramp5 in two rice cultivars. Hydroponic culture and Cd-contaminated paddy field trials showed that $\mathrm{Cd}$ concentrations were dramatically decreased in shoots and roots of osnramp5 mutants. 
As a result of the Fukushima nuclear accident, massive releases of radioactive cesium (Cs) isotopes ${ }^{134} \mathrm{Cs}$ (2-year half-life) and ${ }^{137} \mathrm{Cs}$ (30-year half-life) are expected to have contaminated about half of Japan's soil (Yasunari et al., 2011). Cesium (Cs) is a group I alkali metal with chemical properties similar to potassium $(\mathrm{K})$. Several cloned $\mathrm{K}^{+}$transporters, like HAK/KUP/KT family, can also transport $\mathrm{Cs}^{+}$in the plants (Véry et al., 2014; Scherzer et al., 2015). Nieves-Cordones et al. (2017) used the CRISPR-Cas system to knock out the OsHAK1, resulting in a strong reduction of radioactive cesium contents in mutated plants when grown in Fukushima soil highly contaminated with ${ }^{137} \mathrm{Cs}^{+}$.

\subsubsection{Enzymatic Browning}

Enzymatic browning refers to the process in which polyphenol oxidases (PPOs) catalyze the formation of phenolic substances into quinones in the presence of oxygen, resulting in the formation of dark precipitate in fruits and vegetables and loss of nutritional quality. A lower PPO activity in plants would reduce the enzymatic browning phenotype. González et al. (2020) induced StPPO2 gene mutations in tetraploid potato using CRISPR/Cas9 system. Compared to the control, mutations in the four alleles of the StPPO2 gene resulted in a reduction of PPO activity by up to $69 \%$ and a $73 \%$ reduction in enzymatic browning in tubers.

\subsubsection{Steroidal Glycoalkaloids}

Also, in potatoes, there are high levels of toxic compounds of steroidal glycoalkaloids (SGAs), $\alpha$-solanine and $\alpha$-chaconine, in the flowers and the tuber sprouts. Nakayasu et al. (2018) edited St16DOX encoding a steroid 16a-hydroxylase in SGA biosynthesis, to generate two SGA-free St16DOX-disrupted potato hairy root lines.

\subsubsection{Acrylamide}

Acrylamide in food is a processing contaminant that forms from free asparagine and potentially increases the risk of developing cancer for humans. In wheat, Raffan et al. (2021) knocked out the asparagine synthetase gene TaASN2 using four guide RNAs targeting all three homologues of TaASN2. Compared with the wild type, the concentration of free asparagine in seeds of the plants with all six TaASN2 alleles edited was significantly decreased, up to $90 \%$.

\subsection{Other Improvements}

\subsubsection{Fragrant Aromas}

The fragrant aromas of dishes or staple food keep the mind at ease and improve appetite. The most famous example is the aromatic rice varieties basmati and jasmine rice, with a popcorn-like scent, which are popular worldwide. 2-acetyl-1-pyrroline (2AP) is the key flavour compound in rice aroma volatiles. Rice flavour is mainly controlled by recessive genes OsBadh2/fgr (betaine aldehyde dehydrogenase 2). It is reported that OsBadh2 converts $\gamma$-aminobutyraldehyde (GABald) to gammaaminobutyric acid (GABA), and the reduced or loss of $\mathrm{BADH} 2$ activity promotes the GABald to be converted into 2AP (Bradbury et al., 2005). Comparative sequencing revealed an $8 \mathrm{bp}$ deletion in the $7^{\text {th }}$ exon of OsBadh2 in most fragrant rice varieties, which resulted in the loss of the original function of $B a d h 2$, thus producing fragrance in rice leaves and grains. Based on it, Ashokkumar et al. (2020) employed the CRISPR/Cas9 tool to target the $7^{\text {th }}$ exon of $O s B A D H 2$ and created novel alleles to introduce aromas into an elite non-aromatic rice variety. Similary, Hui et al. (2021) targeted the $7^{\text {th }}$ exon of OsBADH2 in no-fragrant japonica and indica varieties and provided important genetic resources for grain aroma improvement in three-line hybrid rice. Tang et al. (2021) first used CRISPR/Cas9 to delete the exon nucleotide at the exon-intron junction of $\mathrm{OsBADH} 2$, which induces the exon skipping of $\mathrm{OsBADH} 2$, resulting in high $2 \mathrm{AP}$ production and grain fragrance. As rice, naturally fragrant germplasm has been observed in other plants, such as soybean (Juwattanasomran et al., 2011), cucumber (Yundaeng et al., 2015), coconut (Vongvanrungruang et al., 2016), sorghum (Yundaeng et al., 2013), and mung bean (Attar et al., 2017). The 2AP accumulation all results from a loss of function, a weak allele, or lower expression of $B A D H 2$. However, no such germplasm was found in maize. Wang et al. (2021) generated the word's first aromatic maize by simultaneous genome editing of the two $B A D H 2$ genes.

\subsubsection{Long Shelf-Life}

Crop shelf life is a key quality trait in the modern supply chain, especially for fruit and ornamental crops. The short shelf life greatly limits crops' transportation, marketing, and storage, resulting in huge postharvest losses. Ethylene is the natural plant hormone that makes fruits ripen and flowers to senescence quickly. Therefore, genetic modification to reduce endogenous ethylene or impair the ethylene biosynthetic pathway might be an effective method to prolong the shelf life of crops (Elitzur et al., 2016). Ethylene derived from methionine is converted to $\mathrm{S}$ adenosylmethionine (SAM) by SAM synthase, then to 1-aminocyclopropane-1-carboxylic acid (ACC) by ACC synthase and finally to ethylene by ACC oxidase (ACO) (Yang and Hoffman, 1984). Many researches have shown that ACOs are involved in fruit ripening and flower senescence, and the knockout of ACOs can effectively increase the shelf life of crops (Do et al., 2005; Inaba et al., 2007; Huang et al.,2007). Recently, Hu et al. (2021) conducted an RNA-seq analysis on mature green bananas and identified a banana ACO gene Ma07_t19730.1. This gene can be strongly induced by ethephon and inhibited by $1-\mathrm{MCP}$ to a greater extent in the pulp and peel tissues. Under the natural ripening conditions, the CRISPR/Cas9-based MaAC O 1 (Ma07_t19730.1)-disrupted mutants exhibited reduced ethylene production and longer shelf life than the WT. Petunias are favoured by the floricultural industry for their different flower shapes and colours and are used as a bedding plant. However, newly produced individual flowers show rapid senescence in the mother plant. Xu et al. (2020) designed two specific sgRNAs to target PhACO1 of petunias and successfully obtained edited lines with significantly reduced ethylene production and enhanced flower longevity. Some transcription factors (TFs) operating upstream of ethylene biosynthesis pathways also play important roles in regulating the shelf life of crops. As in other climacteric fruits, for example, tomatoes produce much 


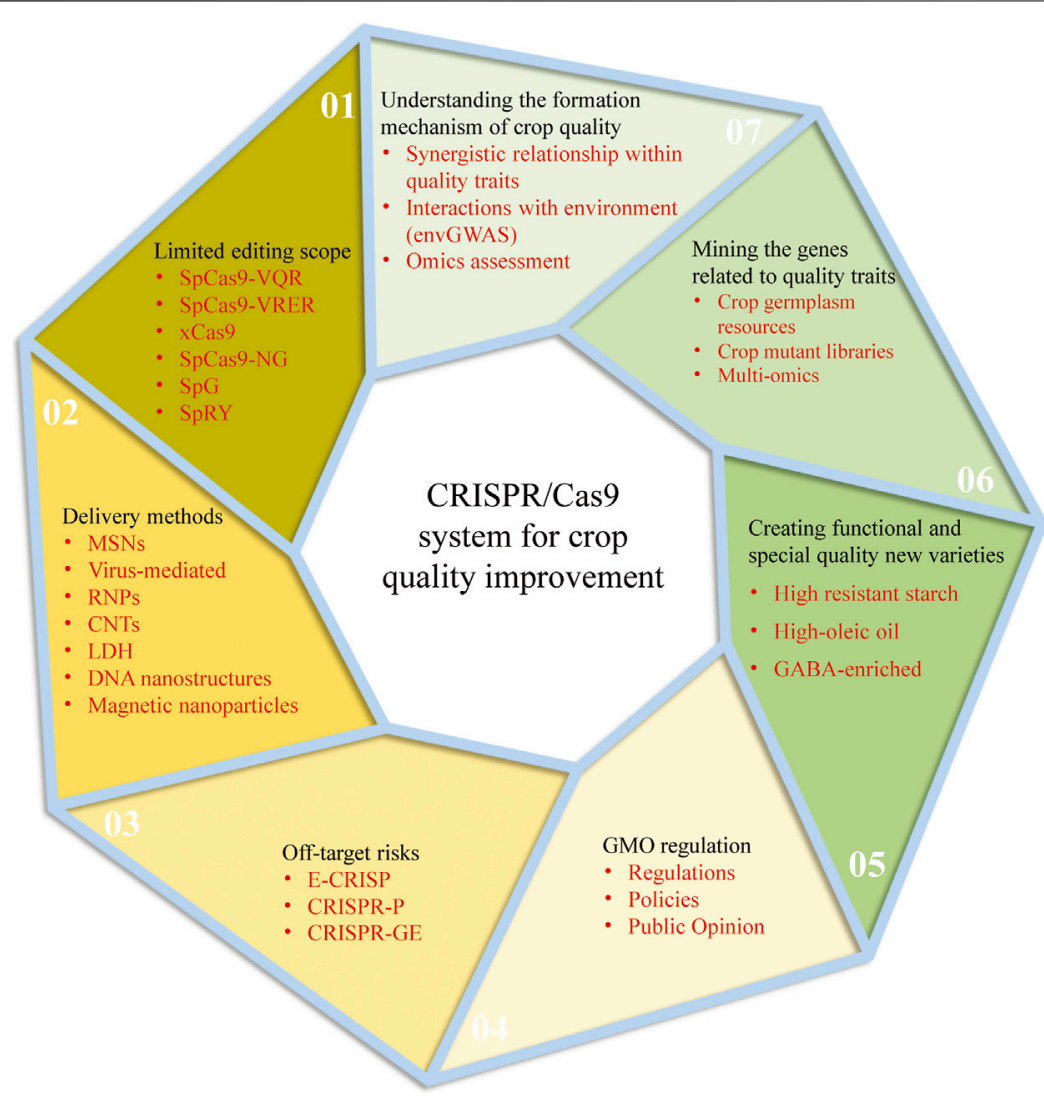

FIGURE 2 | The current challenges and perspectives of the CRISPR/Cas9 system and the future development trend of crop quality improvement.

ethylene during ripening. The use of naturally occurring ripening mutants increases shelf life with a delay in the ripening process, such as $\mathrm{Nr}$ (Never ripe), alc (alcobaca), rin (ripening inhibitor), nor (non-ripening), and Cnr (colorless non-ripening) (Robinson and Tomes, 1968; Tigchelaar et al., 1973; Thompson et al., 1999; Garg et al., 2008). Ito et al. (2015) knocked out the RIN using three sgRNAs to produce incomplete-ripening fruits in which red colour pigmentation was significantly lower than that of the wild type. Similarly, CRISPR-Cnr mutant lines showed delayed fruit ripening phenotype, CRISPR-Nor mutant lines showed partially immature fruit (Gao et al., 2019). The alc mutants were found to have good fruit colour, flavour and resistance to bacterial diseases (Casals et al., 2011). Using the HDR-mediated gene replacement, Yu et al. (2017) successfully replaced ${ }^{317} \mathrm{~T}$ of the ALC gene with ${ }^{317} \mathrm{~A}$ and created a tomato line, significantly prolonged tomato storage time and shelf life. In addition to regulating crop endogenous ethylene content, shelf life is also related to alterations in cuticle properties and remodelling of the fruit cell walls (Keegstra, 2010). Pectin, which is abundant in the primary cell wall (PCWs) and mesenchymal layer (ML) of fruits, has long been known to undergo degradation during ripening (Brummell, 2006). Uluisik et al. (2016) reported a tomato pectate lyase $(P L)$ gene, which is crucial for fruit softening, and the silencing of this $P L$ altered texture without affecting other aspects of ripening. Wang D. et al. (2019) used
CRISPR/Cas9 technology to knock out this gene and obtained similar results.

\section{CHALLENGES AND PERSPECTIVES}

CRISPR/Cas9 system has been rapidly developed and applied since its birth in 2013 with the characteristics of simplicity, high accuracy, short cycle and low cost. However, there are still some unsolved problems in using the CRISPR/Cas9 system for genetic improvement of crop quality. The following will be analyzed from two aspects: the current challenges and perspectives of the CRISPR/Cas9 system and the future development trend of crop quality (Figure 2):

\subsection{Challenges and Perspectives of CRISPR/Cas9 System}

\subsubsection{Limited Editing Scope}

As we all know, the targeting specificity of the CRISPR-Cas9 system is determined by two conditions: one is the specific binding of sgRNA sequence to genomic DNA sequence; another is that Cas9 protein specifically recognizes the protospacer adjacent motif (PAM) on genomic DNA. The Cas9 protein from Streptococcus Pyogenes (SpCas9) is the 
current universal Cas9 protein and specifically recognizes the NGG sequence on DNA as the PAM sequence, limiting the range of DNA sites that Cas9 protein can target. To overcome this limitation, a series of SpCas9 variants derived through protein directed evolution method has greatly expanded the editing range of the CRISPR/Cas system, Such as SpCas9-VQR, SpCas9-VRER, xCas9, SpCas9-NG, and SpG, etc (Hu et al., 2016; Hu et al., 2018; Wang J. et al., 2019; Zhong et al., 2019; Zeng et al., 2020a; Qin et al., 2020; Ren et al., 2021). There is hardly even a restriction on PAM sequences, such as the SpRY variant (Xu Z. et al., 2021; Ren et al., 2021). However, all the above modifications have low editing activity, and further optimization is needed to improve editing efficiency at target sites.

\subsubsection{Off-Target Risks}

Compared with ZFNs and TALENs genome editing techniques, CRISPR/Cas9 system based on gRNA has more advantages in specific recognition. However, due to a large number of genome bases of the edited objects, similar fragments are also widely available. If these similar fragments are recognized, they will cause an off-target effect. This kind of non-specific genome editing is easy to cause uncertainty to the biological response of the edited object, which affects the reliability of this technique in research and application. With the development of high-throughput sequencing technology, many crop genome data are readily available. Based on sequence database, many software or online tools have been developed to aid in designing target sites or evaluating the outcome of genome/gene editing, such as E-CRISP (Heigwer et al., 2014), CRISPR-P (Lei et al., 2014), and CRISPR-GE (Xie et al., 2017), which will enable researchers to examine the specificity of the target sequence further and thus reduce the risk of off-target.

\subsubsection{Delivery Methods}

The robust delivery of CRISPR-Cas9 reagent into plant cells is the basis for the effective application of CRISPR-Cas9 in plants. At present, there are two main methods for plant transformation: biological bombardment and Agrobacterium-mediated transport, but both of them have certain limitations. Agrobacterium-mediated delivery system is the most commonly used tool for plant genetic transformation, but it can only be applied to a small range of plant species or tissues due to the limitations of host genotypes; Biological bombardment can deliver biomolecules to a wide range of plant species or tissue cells, but it is inefficient and risks genome sequence destruction and tissue damage. It should be noted that these traditional methods cannot avoid the lengthy tissue culture process, and the foreign DNA fragments are needed to be integrated into the host genome, thus producing transgenic plants. Therefore, novel delivery strategies are urgently needed. The Cas9 protein-gRNA ribonucleoproteins (RNPs) is one of the most important genomeediting techniques without foreign DNA integration into plant cells. The purified Cas protein and gRNA are preassembled into a CRISPR/Cas RNP complex with complete activity in vitro, which is then directly introduced into plant cells through physical or chemical methods (Woo et al., 2015). This delivery method could avoid transgene integration and off-target mutations. Plant virus systems have also been modified to introduce CRISPR/Cas reagents into plant cell, which are especially helpful for homologous directed recombination mediated gene targeting (Ali et al., 2015; Gil-Humanes et al., 2017; Ellison et al., 2020). In addition, there are studies showed that nano-materials, such as Mesoporous Silica nanoparticles (MSNs), Carbon nanotubes (CNTs), layered double hydroxide (LDH) clay nanosheets, DNA nanostructures, and magnetic nanoparticles, are potential vectors for delivering various forms of CRISPR/Cas reagents (Wang P. et al., 2019; Demirer et al., 2019; Kwak et al., 2019; Zhang et al., 2019). Nano-materials can be diffused through plant cell walls without mechanical assistance and without causing tissue damage. These new genetic transformation technologies are expected to become the most important transformation methods in the future.

\subsubsection{GMO Regulation}

At present, the safety of gene editing products is still controversial. The European Union has approved about 118 genetically modified organisms, but most of them are fed to animals, only a handful of is for human consumption directly. There is almost no genetically modified (GM) food market in Europe; gene-edited crops are considered GM products and regulated (Bruetschy, 2019). While some countries, like the United States, Canada, Australia, Japan, Argentina, and Brazil, have treated gene-edited crops (without foreign genes) as nonGMOs, which are already on the market. For example, browning resistant mushrooms created by gene editing at the University of Pennsylvania in 2016 are not regulated in the United States (Waltz, 2016). Therefore, the commercial application of geneedited crops still needs the support and improvement of relevant regulations, policies and public opinion environment.

\subsection{Developing Trends for Crop Quality Improvement 5.2.1 Systematic Understanding Formation Mechanism of Crop Quality}

Crop quality is a comprehensive and complex character manifested in the interaction with environmental factors, quality, and yield characters. Therefore, many characters often restrict each other during crop quality improvement. For example, nitrogen fertilizer as an environmental factor can promote the increase of rice yield and grain protein content. Although the yield and nutritional quality of rice were improved, the increase of grain protein content significantly decreased the rice eating and cooking quality (Yang et al., 2015; Yang et al., 2020). In the breeding process, rice yield and grain quality are often difficult to balance. In the future studies, besides focusing on a certain quality trait, attentions should also be paid to studying the synergistic relationship within different quality or yield characters and their interactions with environment. The genetic basis, molecular network and metabolic regulation mechanism of quality traits should be studied from multiple dimensions such as transcriptome, proteome and metabolome. It is worth mentioning that the envGWAS, which uses environmental or non-genetic variables as traits in GWAS to 
map loci associated with those variables, is an effective and popular way in such studies. This approach has been used to analysis impact of many environmental factors on crop traits, such as geographical location, climate, soil, even age and so on ( $\mathrm{Li}$ J. et al., 2019; Millet et al., 2019; Sharma et al., 2020).

\subsubsection{Multi-Strategy Mining of Genes Related to Quality Traits}

With the development of functional genomics and molecular biology, many genes controlling important quality traits have been successfully cloned, such as $W x, B A D H 2, F A D 2$, etc. However, compared with yield traits, the study of crop quality traits started late and was even blank in some crops with complex genetic backgrounds. Therefore, further exploration of key genes controlling quality is the precursor and basis of quality genetic improvement. We can conduct gene mining through the following strategies: 1) Crop germplasm resources are a treasure-house of abundant genetic variation. By extensively collecting crop germplasm resources, systematically evaluating quality traits and screening excellent germplasm resources, it can provide a guarantee for digging quality genes and identifying excellent alleles; 2) Using chemical, radial mutagenesis or gene-editing techniques to create crop mutant libraries to screen the mutants with changed quality traits and clone related genes; 3) Using the multi-omics method to explore quality-related genes, especially to identify key genes that respond to environmental variation, which is helpful to reveal the interaction between genetic variation and environmental variation.

\subsubsection{Creation of Functional and Special Quality New Varieties}

At present, people are faced with the dual challenges of nutritional deficiency and overnutrition. Taking in too much

\section{REFERENCES}

Abe, K., Araki, E., Suzuki, Y., Toki, S., and Saika, H. (2018). Production of High Oleic/low Linoleic rice by Genome Editing. Plant Physiol. Biochem. 131, 58-62. doi:10.1016/j.plaphy.2018.04.033

Akama, K., Akter, N., Endo, H., Kanesaki, M., Endo, M., and Toki, S. (2020). An In Vivo Targeted Deletion of the Calmodulin-Binding Domain from Rice Glutamate Decarboxylase 3 (OsGAD3) Increases $\gamma$-Aminobutyric Acid Content in Grains. Rice 13, 20. doi:10.1186/s12284-020-00380-w

Al Amin, N., Ahmad, N., Wu, N., Pu, X., Ma, T., Du, Y., et al. (2019). CRISPR-Cas9 Mediated Targeted Disruption of FAD2-2 Microsomal omega-6 Desaturase in Soybean (Glycine max.L). BMC Biotechnol. 19, 9. doi:10.1186/s12896-0190501-2

Ali, Z., Abul-faraj, A., Li, L., Ghosh, N., Piatek, M., Mahjoub, A., et al. (2015). Efficient Virus-Mediated Genome Editing in Plants Using the CRISPR/Cas9 System. Mol. Plant 8, 1288-1291. doi:10.1016/j.molp.2015.02.011

Anzalone, A. V., Randolph, P. B., Davis, J. R., Sousa, A. A., Koblan, L. W., Levy, J. M., et al. (2019). Search-and-replace Genome Editing without Double-Strand Breaks or Donor DNA. Nature 576 (7785), 149-157. doi:10.1038/s41586-0191711-4

Ashokkumar, S., Jaganathan, D., Ramanathan, V., Rahman, H., Palaniswamy, R., Kambale, R., et al. (2020). Creation of Novel Alleles of Fragrance Gene OsBADH2 in rice through CRISPR/Cas9 Mediated Gene Editing. PLoS One 15, e0237018. doi:10.1371/journal.pone.0237018 sugar or lipid due to unreasonable diet structure leads to overnutrition and induces obesity, cardiovascular disease, diabetes, and kidney disease. In addition, due to unbalanced regional economic development and natural conditions, the "lack of nutrition" and "hidden hunger" problems are also more prominent, such as nutritional anaemia and vitamin A deficiency. Chronic diseases related to diet and nutrition are increasingly threatening people's health. Based on this, the concepts of "nutrition-oriented agriculture" and "functional agriculture" have attracted more attention, and people are gradually accepting the preventive and therapeutic effects of nutrition-healthy food and functional food. At present, biofortification crops with the significant increase of one or more nutrients can be obtained by molecular design breeding or gene-editing methods, such as high resistant starch rice, giant embryo rice, golden rice, etc., but the progress is still slow. In the future, we need to further search for functional germplasm resources, analyze the synthesis and metabolic pathways of relevant bioactive compounds and their regulatory mechanisms, and create more new crop germplasm with high nutrition or special functions.

\section{AUTHOR CONTRIBUTIONS}

YY, CX, ZS, and CY wrote the manuscript.

\section{FUNDING}

This work was funded by Natural Science Foundation of Jiangsu Province (No. BK20210798), National Natural Science Foundation of China (No. 31871241, 31970519), and Natural Science Foundation of Jiangsu Province (BE2021334-1).

Attar, U., Hinge, V., Zanan, R., Adhav, R., and Nadaf, A. (2017). Identification of Aroma Volatiles and Understanding 2-Acetyl-1-Pyrroline Biosynthetic Mechanism in Aromatic Mung Bean (Vigna Radiata (L.) Wilczek). Physiol. Mol. Biol. Plants. 23, 443-451. doi:10.1007/s12298-017-0414-2

Bachtiar, V., Near, J., Johansen-Berg, H., and Stagg, C. J. (2015). Modulation of GABA and Resting State Functional Connectivity by Transcranial Direct Current Stimulation. Elife 4, e08789. doi:10.7554/eLife.08789

Baltes, N. J., Gil-Humanes, J., Cermak, T., Atkins, P. A., and Voytas, D. F. (2014). DNA Replicons for Plant Genome Engineering. Plant Cell 26, 151-163. doi:10.1105/tpc.113.119792

Begemann, M. B., Gray, B. N., January, E., Gordon, G. C., He, Y., Liu, H., et al. (2017). Precise Insertion and Guided Editing of Higher Plant Genomes Using Cpf1 CRISPR Nucleases. Sci. Rep. 7, 11606. doi:10.1038/s41598-017-11760-6

Bertin, G., and Averbeck, D. (2006). Cadmium: Cellular Effects, Modifications of Biomolecules, Modulation of DNA Repair and Genotoxic Consequences. Biochimie 88, 1549-1559. doi:10.1016/j.biochi.2006.10.001

Bharat, S. S., Li, S., Li, J., Yan, L., and Xia, L. (2020). Base Editing in Plants: Current Status and Challenges. Crop J. 8, 384-395. doi:10.1016/j.cj.2019.10.002

Bhati, K. K., Aggarwal, S., Sharma, S., Mantri, S., Singh, S. P., Bhalla, S., et al. (2014). Differential Expression of Structural Genes for the Late Phase of Phytic Acid Biosynthesis in Developing Seeds of Wheat (Triticum aestivum L.). Plant Sci. 224, 74-85. doi:10.1016/j.plantsci.2014.04.009

Biermann, U., Bornscheuer, U., Meier, M. A. R., Metzger, J. O., and Schäfer, H. J. (2011). Oils and Fats as Renewable Raw Materials in Chemistry. Angew. Chem. Int. Ed. 50, 3854-3871. doi:10.1002/anie.201002767 
Bradbury, L. M. T., Fitzgerald, T. L., Henry, R. J., Jin, Q., and Waters, D. L. E. (2005). The Gene for Fragrance in rice. Plant Biotechnol. J. 3, 363-370. doi:10.1111/j.1467-7652.2005.00131.x

Bruetschy, C. (2019). The EU Regulatory Framework on Genetically Modified Organisms (GMOs). Transgenic Res. 28, 169-174. doi:10.1007/s11248-01900149-y

Brummell, D. A. (2006). Cell wall Disassembly in Ripening Fruit. Funct. Plant Biol. 33, 103-119. doi:10.1071/FP05234

Bull, S. E., Seung, D., Chanez, C., Mehta, D., Kuon, J.-E., Truernit, E., et al. (2018). Accelerated Ex Situ Breeding of GBSS - and PTST1 -edited Cassava for Modified Starch. Sci. Adv. 4, eaat6086. doi:10.1126/sciadv.aat6086

Casals, J., Cebolla-Cornejo, J., Roselló, S., Beltrán, J., Casañas, F., and Nuez, F. (2011). Long-term Postharvest Aroma Evolution of Tomatoes with the Alcobaça (Alc) Mutation. Eur. Food Res. Technol. 233, 331-342. doi:10.1007/s00217-011-1517-6

Čermák, T., Baltes, N. J., Čegan, R., Zhang, Y., and Voytas, D. F. (2015). Highfrequency, Precise Modification of the Tomato Genome. Genome Biol. 16, 232. doi:10.1186/s13059-015-0796-9

Chapman, J. R., Taylor, M. R. G., and Boulton, S. J. (2012). Playing the End Game: DNA Double-Strand Break Repair Pathway Choice. Mol. Cell 47, 497-510. doi:10.1016/j.molcel.2012.07.029

Chen, Y., Zhou, X.-R., Zhang, Z.-J., Dribnenki, P., Singh, S., and Green, A. (2015). Development of High Oleic Oil Crop Platform in Flax through RNAi-Mediated Multiple FAD2 Gene Silencing. Plant Cell Rep 34, 643-653. doi:10.1007/s00299015-1737-5

Cho, S. W., Kim, S., Kim, J. M., and Kim, J.-S. (2013). Targeted Genome Engineering in Human Cells with the Cas9 RNA-Guided Endonuclease. Nat. Biotechnol. 31, 230-232. doi:10.1038/nbt.2507

Cong, L., Ran, F. A., Cox, D., Lin, S., Barretto, R., Habib, N., et al. (2013). Multiplex Genome Engineering Using CRISPR/Cas Systems. Science 339, 819-823. doi:10.1126/science. 1231143

Davis, J. P., Dean, L. O., Faircloth, W. H., and Sanders, T. H. (2008). Physical and Chemical Characterizations of normal and High-Oleic Oils from Nine Commercial Cultivars of Peanut. J. Am. Oil Chem. Soc. 85, 235-243. doi:10.1007/s11746-007-1190-x

Demirer, G. S., Zhang, H., Matos, J. L., Goh, N. S., Cunningham, F. J., Sung, Y., et al. (2019). High Aspect Ratio Nanomaterials Enable Delivery of Functional Genetic Material without DNA Integration in Mature Plants. Nat. Nanotechnol. 14, 456-464. doi:10.1038/s41565-019-0382-5

Deng, L., Wang, H., Sun, C., Li, Q., Jiang, H., Du, M., et al. (2018). Efficient Generation of Pink-Fruited Tomatoes Using CRISPR/Cas9 System. J. Genet. Genomics 45, 51-54. doi:10.1016/j.jgg.2017.10.002

Ding, Y., Zhu, J., Zhao, D., Liu, Q., Yang, Q., and Zhang, T. (2021). Targeting CisRegulatory Elements for Rice Grain Quality Improvement. Front. Plant Sci. 12, 705834. doi:10.3389/fpls.2021.705834

Do, P. T., Nguyen, C. X., Bui, H. T., Tran, L. T. N., Stacey, G., Gillman, J. D., et al. (2019). Demonstration of Highly Efficient Dual gRNA CRISPR/Cas9 Editing of the Homeologous GmFAD2-1A and GmFAD2-1B Genes to Yield a High Oleic, Low Linoleic and a-linolenic Acid Phenotype in Soybean. BMC Plant Biol. 19, 311. doi:10.1186/s12870-019-1906-8

Do, Y.-Y., Thay, T.-S., Chang, T.-W., and Huang, P.-L. (2005). Molecular Cloning and Characterization of a Novel 1-Aminocyclopropane-1-Carboxylate Oxidase Gene Involved in Ripening of Banana Fruits. J. Agric. Food Chem. 53, 8239-8247. doi:10.1021/jf051224+

Doebley, J. (2004). The Genetics of maize Evolution. Annu. Rev. Genet. 38, 37-59. doi:10.1146/annurev.genet.38.072902.092425

Dong, L., Qi, X., Zhu, J., Liu, C., Zhang, X., Cheng, B., et al. (2019). Supersweet and Waxy: Meeting the Diverse Demands for Specialty maize by Genome Editing. Plant Biotechnol. J. 17, 1853-1855. doi:10.1111/pbi.13144

Dong, O. X., Yu, S., Jain, R., Zhang, N., Duong, P. Q., Butler, C., et al. (2020). Markerfree Carotenoid-Enriched rice Generated through Targeted Gene Insertion Using CRISPR-Cas9. Nat. Commun. 11, 1178. doi:10.1038/s41467-020-14981-y

Elitzur, T., Yakir, E., Quansah, L., Zhangjun, F., Vrebalov, J., Khayat, E., et al. (2016). Banana MaMADS Transcription Factors Are Necessary for Fruit Ripening and Molecular Tools to Promote Shelf-Life and Food Security. Plant Physiol. 171, 380-391. doi:10.1104/pp.15.01866

Ellison, E. E., Nagalakshmi, U., Gamo, M. E., Huang, P.-j., Dinesh-Kumar, S., and Voytas, D. F. (2020). Multiplexed Heritable Gene Editing Using RNA Viruses and mobile Single Guide RNAs. Nat. Plants 6, 620-624. doi:10.1038/s41477020-0670-y

Emmambux, M. N., and Taylor, J. R. N. (2016). "Starch: Nutritional and Health Aspects," in Carbohydrates in Food. Editor A.-C. Eliasson (Boca Raton: CRC Press Taylor \& Francis Group), 579-626. doi:10.1201/9781315372822-12

Fan, C., Hao, M., Jia, Z., Neri, C., Chen, X., Chen, W., et al. (2021). Some Characteristics of Crossing over in Induced Recombination between Chromosomes of Wheat and rye. Plant J. 105, 1665-1676. doi:10.1111/ tpj. 15140

Fauser, F., Schiml, S., and Puchta, H. (2014). Both CRISPR/Cas-based Nucleases and Nickases Can Be Used Efficiently for Genome Engineering inArabidopsis Thaliana. Plant J. 79, 348-359. doi:10.1111/tpj.12554

Fei, Y., Yang, J., Wang, F., Fan, F., Li, W., Jun, W., et al. (2019). Production of Two Elite Glutinous rice Varieties by Editing Wx Gene. Rice Sci. 26, 118-124. doi:10.1016/j.rsci.2018.04.007

Feng, Z., Mao, Y., Xu, N., Zhang, B., Wei, P., Yang, D.-L., et al. (2014). Multigeneration Analysis Reveals the Inheritance, Specificity, and Patterns of CRISPR/Cas-induced Gene Modifications in Arabidopsis. Proc. Natl. Acad. Sci. 111, 4632-4637. doi:10.1073/pnas.1400822111

Feng, Z., Zhang, B., Ding, W., Liu, X., Yang, D.-L., Wei, P., et al. (2013). Efficient Genome Editing in Plants Using a CRISPR/Cas System. Cell Res 23, 1229-1232. doi:10.1038/cr.2013.114

Frary, A., Nesbitt, T. C., Frary, A., Grandillo, S., Knaap, E. v. d., Cong, B., et al. (2000). fw2.2 : A Quantitative Trait Locus Key to the Evolution of Tomato Fruit Size. Science 289, 85-88. doi:10.1126/science.289.5476.85

Furukawa, T., Maekawa, M., Oki, T., Suda, I., Iida, S., Shimada, H., et al. (2007). The $R c$ and $R d$ Genes Are Involved in Proanthocyanidin Synthesis in rice Pericarp. Plant J. 49, 91-102. doi:10.1111/j.1365-313X.2006.02958.x

Gao, C. (2021). Genome Engineering for Crop Improvement and Future Agriculture. Cell 184 (6), 1621-1635. doi:10.1016/j.cell.2021.01.005

Gao, H., Gadlage, M. J., Lafitte, H. R., Lenderts, B., Yang, M., Schroder, M., et al. (2020). Superior Field Performance of Waxy Corn Engineered Using CRISPRCas9. Nat. Biotechnol. 38, 579-581. doi:10.1038/s41587-020-0444-0

Gao, Y., Zhu, N., Zhu, X., Wu, M., Jiang, C.-Z., Grierson, D., et al. (2019). Diversity and Redundancy of the Ripening Regulatory Networks Revealed by the fruitENCODE and the New CRISPR/Cas9 CNR and NOR Mutants. Hortic. Res. 6, 39. doi:10.1038/s41438-019-0122-x

Garg, N., Cheema, D. S., and Dhatt, A. S. (2008). Genetics of Yield, Quality and Shelf Life Characteristics in Tomato under normal and Late Planting Conditions. Euphytica 159, 275-288. doi:10.1007/s10681-007-9486-3

Gaudelli, N. M., Komor, A. C., Rees, H. A., Packer, M. S., Badran, A. H., Bryson, D. I., et al. (2017). Programmable Base Editing of at to GC in Genomic DNA without DNA Cleavage. Nature 551, 464-471. doi:10.1038/nature24644

Gil-Humanes, J., Wang, Y., Liang, Z., Shan, Q., Ozuna, C. V., Sánchez-León, S., et al. (2017). High-efficiency Gene Targeting in Hexaploid Wheat Using DNA Replicons and CRISPR/Cas9. Plant J. 89, 1251-1262. doi:10.1111/tpj.13446

González, M. N., Massa, G. A., Andersson, M., Turesson, H., Olsson, N., Fält, A.-S., et al. (2020). Reduced Enzymatic Browning in Potato Tubers by Specific Editing of a Polyphenol Oxidase Gene via Ribonucleoprotein Complexes Delivery of the CRISPR/Cas9 System. Front. Plant Sci. 10, 1649. doi:10.3389/fpls.2019.01649

Grissa, I., Vergnaud, G., and Pourcel, C. (2007). CRISPRFinder: a Web Tool to Identify Clustered Regularly Interspaced Short Palindromic Repeats. Nucleic Acids Res. 35, W52-W57. doi:10.1093/nar/gkm360

He, L., Xiufeng, L., Yang, X., Hualong, L., Mingliang, H., Xiaojie, T., et al. (2020c). High-efficiency Reduction of rice Amylose Content via CRISPR/Cas9-mediated Base Editing. Rice Sci. 27, 445-448. doi:10.1016/j.rsci.2020.09.001

Heigwer, F., Kerr, G., and Boutros, M. (2014). E-crisp: Fast CRISPR Target Site Identification. Nat. Methods 11 (2), 122-123. doi:10.1038/nmeth.2812

Hendelman, A., Zebell, S., Rodriguez-Leal, D., Dukler, N., Robitaille, G., Wu, X., et al. (2021). Conserved Pleiotropy of an Ancient Plant Homeobox Gene Uncovered by Cis-Regulatory Dissection. Cell 184, 1724-1739.e16. doi:10.1016/j.cell.2021.02.001

Heppell, L. M. J., Sissons, J. W., and Pedersen, H. E. (1987). A Comparison of the Antigenicity of Soya-Bean-Based Infant Formulas. Br. J. Nutr. 58, 393-403. doi:10.1079/bjn19870108

Heyer, W.-D., Ehmsen, K. T., and Liu, J. (2010). Regulation of Homologous Recombination in Eukaryotes. Annu. Rev. Genet. 44, 113-139. doi:10.1146/ annurev-genet-051710-150955 
Hsu, P. D., Lander, E. S., and Zhang, F. (2014). Development and Applications of CRISPR-Cas9 for Genome Engineering. Cell 157, 1262-1278. doi:10.1016/ j.cell.2014.05.010

Hu, C., Sheng, O., Deng, G., He, W., Dong, T., Yang, Q., et al. (2021). CRISPR/ Cas9-mediated Genome Editing of MaACO1 (Aminocyclopropane-1carboxylate Oxidase 1) Promotes the Shelf Life of Banana Fruit. Plant Biotechnol. J. 19, 654-656. doi:10.1111/pbi.13534

Hu, X., Meng, X., Liu, Q., Li, J., and Wang, K. (2018). Increasing the Efficiency of CRISPR-Cas9-VQR Precise Genome Editing in rice. Plant Biotechnol. J. 16, 292-297. doi:10.1111/pbi.12771

Hu, X., Wang, C., Fu, Y., Liu, Q., Jiao, X., and Wang, K. (2016). Expanding the Range of CRISPR/Cas9 Genome Editing in Rice. Mol. Plant 9, 943-945. doi:10.1016/j.molp.2016.03.003

Huang, H., Cui, T., Zhang, L., Yang, Q., Yang, Y., Xie, K., et al. (2020a). Modifications of Fatty Acid Profile through Targeted Mutation at BnaFAD2 Gene with CRISPR/Cas9-mediated Gene Editing in Brassica Napus. Theor. Appl. Genet. 133, 2401-2411. doi:10.1007/s00122-020-03607-y

Huang, L.-C., Lai, U.-L., Yang, S.-F., Chu, M.-J., Kuo, C.-I., Tsai, M.-F., et al. (2007). Delayed Flower Senescence of Petunia Hybrida Plants Transformed with Antisense Broccoli ACC Synthase and ACC Oxidase Genes. Postharvest Biol. Tech. 46, 47-53. doi:10.1016/j.postharvbio.2007.03.015

Huang, L., Li, Q., Zhang, C., Chu, R., Gu, Z., Tan, H., et al. (2020b). Creating Novel Wx Alleles with fine-tuned Amylose Levels and Improved Grain Quality in rice by Promoter Editing Using CRISPR/Cas9 System. Plant Biotechnol. J. 18, 2164-2166. doi:10.1111/pbi.13391

Hui, S., Li, H., Mawia, A. M., Zhou, L., Cai, J., Ahmad, S., et al. (2021). Production of Aromatic Three-line Hybrid rice Using Novel Alleles of BADH2. Plant Biotechnol. J. 20, 59-74. doi:10.1111/pbi.13695

Hummel, A. W., Chauhan, R. D., Cermak, T., Mutka, A. M., Vijayaraghavan, A., Boyher, A., et al. (2018). Allele Exchange at the EPSPS Locus Confers Glyphosate Tolerance in Cassava. Plant Biotechnol. J. 16, 1275-1282. doi:10.1111/pbi.12868

Inaba, A., Liu, X., Yokotani, N., Yamane, M., Lu, W.-J., Nakano, R., et al. (2007). Differential Feedback Regulation of Ethylene Biosynthesis in Pulp and Peel Tissues of Banana Fruit. J. Exp. Bot. 58, 1047-1057. doi:10.1093/jxb/erl265

Ishikawa, S., Ishimaru, Y., Igura, M., Kuramata, M., Abe, T., Senoura, T., et al. (2012). Ion-beam Irradiation, Gene Identification, and Marker-Assisted Breeding in the Development of Low-Cadmium rice. Proc. Natl. Acad. Sci. 109, 19166-19171. doi:10.1073/pnas.1211132109

Ito, Y., Nishizawa-Yokoi, A., Endo, M., Mikami, M., and Toki, S. (2015). CRISPR/ Cas9-mediated Mutagenesis of the RIN Locus that Regulates Tomato Fruit Ripening. Biochem. Biophysical Res. Commun. 467, 76-82. doi:10.1016/ j.bbrc.2015.09.117

Jinek, M., Chylinski, K., Fonfara, I., Hauer, M., Doudna, J. A., and Charpentier, E. (2012). A Programmable Dual-RNA-Guided DNA Endonuclease in Adaptive Bacterial Immunity. Science 337, 816-821. doi:10.1126/science.1225829

Jobling, S. (2004). Improving Starch for Food and Industrial Applications. Curr. Opin. Plant Biol. 7, 210-218. doi:10.1016/j.pbi.2003.12.001

Jung, J. H., Kim, H., Go, Y. S., Lee, S. B., Hur, C.-G., Kim, H. U., et al. (2011). Identification of Functional BrFAD2-1 Gene Encoding Microsomal delta-12 Fatty Acid Desaturase from Brassica Rapa and Development of Brassica Napus Containing High Oleic Acid Contents. Plant Cell Rep 30, 1881-1892. doi:10.1007/s00299-011-1095-x

Juwattanasomran, R., Somta, P., Chankaew, S., Shimizu, T., Wongpornchai, S., Kaga, A., et al. (2011). A SNP in GmBADH2 Gene Associates with Fragrance in Vegetable Soybean Variety "Kaori" and SNAP Marker Development for the Fragrance. Theor. Appl. Genet. 122, 533-541. doi:10.1007/s00122-010-1467-6

Karanam, K., Kafri, R., Loewer, A., and Lahav, G. (2012). Quantitative Live Cell Imaging Reveals a Gradual Shift between DNA Repair Mechanisms and a Maximal Use of HR in Mid S Phase. Mol. Cell 47, 320-329. doi:10.1016/ j.molcel.2012.05.052

Keegstra, K. (2010). Plant Cell Walls: Figure 1. Plant Physiol. 154, 483-486. doi:10.1104/pp.110.161240

Khan, M. S. S., Basnet, R., Islam, S. A., and Shu, Q. (2019). Mutational Analysis of OsPLDa1 Reveals its Involvement in Phytic Acid Biosynthesis in Rice Grains. J. Agric. Food Chem. 67, 11436-11443. doi:10.1021/acs.jafc.9b05052

Komor, A. C., Kim, Y. B., Packer, M. S., Zuris, J. A., and Liu, D. R. (2016). Programmable Editing of a Target Base in Genomic DNA without DoubleStranded DNA Cleavage. Nature 533, 420-424. doi:10.1038/nature17946
Konishi, S., Izawa, T., Lin, S. Y., Ebana, K., Fukuta, Y., Sasaki, T., et al. (2006). An SNP Caused Loss of Seed Shattering during rice Domestication. Science 312, 1392-1396. doi:10.1126/science.1126410

Kuang, Y., Li, S., Ren, B., Yan, F., Spetz, C., Li, X., et al. (2020). Base-EditingMediated Artificial Evolution of OsAls1 in Planta to Develop Novel HerbicideTolerant Rice Germplasms. Mol. Plant 13, 565-572. doi:10.1016/ j.molp.2020.01.010

Kuo, H.-F., Hsu, Y.-Y., Lin, W.-C., Chen, K.-Y., Munnik, T., Brearley, C. A., et al. (2018). Arabidopsis Inositol Phosphate Kinases IPK1 and ITPK1 Constitute a Metabolic Pathway in Maintaining Phosphate Homeostasis. Plant J. 95, 613-630. doi:10.1111/tpj.1397410.1111/tpj.13974

Kurihara, Y. (2020). uORF Shuffling Fine-Tunes Gene Expression at a Deep Level of the Process. Plants 9, 608. doi:10.3390/plants9050608

Kwak, S.-Y., Lew, T. T. S., Sweeney, C. J., Koman, V. B., Wong, M. H., BohmertTatarev, K., et al. (2019). Chloroplast-selective Gene Delivery and Expression in Planta Using Chitosan-Complexed Single-Walled Carbon Nanotube Carriers. Nat. Nanotechnol. 14, 447-455. doi:10.1038/s41565019-0375-4

Lee, K.-R., Jeon, I., Yu, H., Kim, S.-G., Kim, H.-S., Ahn, S.-J., et al. (2021). Increasing Monounsaturated Fatty Acid Contents in Hexaploid Camelina Sativa Seed Oil by FAD2 Gene Knockout Using CRISPR-Cas9. Front. Plant Sci. 12, 702930. doi:10.3389/fpls.2021.702930

Lee, K.-R., Kim, E.-H., Roh, K. H., Kim, J.-B., Kang, H.-C., Go, Y. S., et al. (2016). High-oleic Oilseed Rapes Developed with Seed-specific Suppression of FAD2 Gene Expression. Appl. Biol. Chem. 59, 669-676. doi:10.1007/s13765-0160208-1

Lee, Y.-H., Park, W., Kim, K.-S., Jang, Y.-S., Lee, J.-E., Cha, Y.-L., et al. (2018). EMS-induced Mutation of an Endoplasmic Reticulum Oleate Desaturase Gene (FAD2-2) Results in Elevated Oleic Acid Content in Rapeseed (Brassica Napus L.). Euphytica 214, 1-12. doi:10.1007/s10681-017-2106-y

Lei, Y., Lu, L., Liu, H.-Y., Li, S., Xing, F., and Chen, L.-L. (2014). CRISPR-P: A Web Tool for Synthetic Single-Guide RNA Design of CRISPR-System in Plants. Mol. Plant 7, 1494-1496. doi:10.1093/mp/ssu044

Li, A., Jia, S., Yobi, A., Ge, Z., Sato, S. J., Zhang, C., et al. (2018a). Editing of an Alpha-Kafirin Gene Family Increases, Digestibility and Protein Quality in Sorghum. Plant Physiol. 177, 1425-1438. doi:10.1104/pp.18.00200

Li, C., Li, W., Zhou, Z., Chen, H., Xie, C., and Lin, Y. (2020a). A New rice Breeding Method: CRISPR/Cas9 System Editing of the Xa13 Promoter to Cultivate Transgene-free Bacterial Blight-resistant rice. Plant Biotechnol. J. 18, 313-315. doi:10.1111/pbi.13217

Li, C., Zhang, R., Meng, X., Chen, S., Zong, Y., Lu, C., et al. (2020b). Targeted, Random Mutagenesis of Plant Genes with Dual Cytosine and Adenine Base Editors. Nat. Biotechnol. 38, 875-882. doi:10.1038/s41587-019-0393-7

Li, J., Jiao, G., Sun, Y., Chen, J., Zhong, Y., Yan, L., et al. (2021). Modification of Starch Composition, Structure and Properties through Editing of TaSBEIIa in Both winter and spring Wheat Varieties by CRISPR/Cas9. Plant Biotechnol. J. 19, 937-951. doi:10.1111/pbi.13519

Li, J., Li, H., Chen, J., Yan, L., and Xia, L. (2020d). Toward Precision Genome Editing in Crop Plants. Mol. Plant 13 (6), 811-813. doi:10.1016/ j.molp.2020.04.008

Li, J., Zhang, X., Sun, Y., Zhang, J., Du, W., Guo, X., et al. (2018b). Efficient Allelic Replacement in rice by Gene Editing: A Case Study of the NRT1.1B Gene. J. Integr. Plant Biol. 60, 536-540. doi:10.1111/jipb.12650

Li, J., Chen, G., Rasheed, A., Li, D., Du, W., Sonder, K., et al. (2019). Identifying Loci With Breeding Potential Across Temperate and Tropical Adaptation Via EigenGWAS and EnvGWAS. Mol. Ecol. 28, 3544-3560. doi:10.1111/mec.15169

Li, R., Li, R., Li, X., Fu, D., Zhu, B., Tian, H., et al. (2018c). Multiplexed CRISPR/ Cas9-mediated Metabolic Engineering of $\gamma$-aminobutyric Acid Levels in Solanum lycopersicum. Plant Biotechnol. J. 16, 415-427. doi:10.1111/pbi.12781

Li, S., Li, J., He, Y., Xu, M., Zhang, J., Du, W., et al. (2019). Precise Gene Replacement in rice by RNA Transcript-Templated Homologous Recombination. Nat. Biotechnol. 37, 445-450. doi:10.1038/s41587-019-0065-7

Li, S., Li, J., Zhang, J., Du, W., Fu, J., Sutar, S., et al. (2018). Synthesis-dependent Repair of Cpf1-Induced Double Strand DNA Breaks Enables Targeted Gene Replacement in rice. J. Exp. Bot. 69, 4715-4721. doi:10.1093/jxb/ery245

Li, S., and Xia, L. (2020). Precise Gene Replacement in Plants through CRISPR/Cas Genome Editing Technology: Current Status and Future Perspectives. aBIOTECH 1, 58-73. doi:10.1007/s42994-019-00009-7 
Li, Y., Liu, D., Zong, Y., Jiang, L., Xi, X., Cao, D., et al. (2020e). New D Hordein Alleles Were Created in Barley Using CRISPR/Cas9 Genome Editing. Cereal Res. Commun. 48, 131-138. doi:10.1007/s42976-020-00023-2

Lin, Q., Jin, S., Zong, Y., Yu, H., Zhu, Z., Liu, G., et al. (2021). High-efficiency Prime Editing with Optimized, Paired pegRNAs in Plants. Nat. Biotechnol. 39, 923-927. doi:10.1038/s41587-021-00868-w

Lin, Q., Zong, Y., Xue, C., Wang, S., Jin, S., Zhu, Z., et al. (2020). Prime Genome Editing in rice and Wheat. Nat. Biotechnol. 38 (5), 582-585. doi:10.1038/ s41587-020-0455-x

Lin, T., Zhu, G., Zhang, J., Xu, X., Yu, Q., Zheng, Z., et al. (2014). Genomic Analyses Provide Insights into the History of Tomato Breeding. Nat. Genet. 46, 1220-1226. doi:10.1038/ng.3117

Liu, L., Gallagher, J., Arevalo, E. D., Chen, R., Skopelitis, T., Wu, Q., et al. (2021). Enhancing Grain-Yield-Related Traits by CRISPR-Cas9 Promoter Editing of maize CLE Genes. Nat. Plants 7, 287-294. doi:10.1038/s41477-021-00858-5

Liu, M., Rehman, S., Tang, X., Gu, K., Fan, Q., Chen, D., et al. (2019). Methodologies for Improving HDR Efficiency. Front. Genet. 9, 691. doi:10.3389/fgene.2018.00691

Luo, J., Li, S., Xu, J., Yan, L., Ma, Y., and Xia, L. (2021). Pyramiding Favorable Alleles in an Elite Wheat Variety in One Generation by CRISPR-Cas9-Mediated Multiplex Gene Editing. Mol. Plant 14, 847-850. doi:10.1016/ j.molp.2021.03.024

Luo, M., Gilbert, B., and Ayliffe, M. (2016). Applications of CRISPR/Cas9 Technology for Targeted Mutagenesis, Gene Replacement and Stacking of Genes in Higher Plants. Plant Cell Rep 35, 1439-1450. doi:10.1007/s00299-0161989-8

Ma, X., Zhang, Q., Zhu, Q., Liu, W., Chen, Y., Qiu, R., et al. (2015). A Robust CRISPR/Cas9 System for Convenient, High-Efficiency Multiplex Genome Editing in Monocot and Dicot Plants. Mol. Plant 8, 1274-1284. doi:10.1016/ j.molp.2015.04.007

Makarova, K. S., Haft, D. H., Barrangou, R., Brouns, S. J. J., Charpentier, E., Horvath, P., et al. (2011). Evolution and Classification of the CRISPR-Cas Systems. Nat. Rev. Microbiol. 9, 467-477. doi:10.1038/nrmicro2577

Makarova, K. S., and Koonin, E. V. (2015). Annotation and Classification of CRISPR-Cas Systems. Methods Mol. Biol. 1311, 47-75. doi:10.1007/978-14939-2687-9_4

Mali, P., Yang, L., Esvelt, K. M., Aach, J., Guell, M., DiCarlo, J. E., et al. (2013). RNA-guided Human Genome Engineering via Cas9. Science 339, 823-826. doi:10.1126/science.1232033

Millet, E., Kruijer, W., Krol, E., Coupel-Ledru, A., Prado, S., Cabrera-Bosquet, L., et al. (2019). Genomic Prediction of Maize Yield Across European Environmental Conditions[J]. Nat. Genet. 51, 6. doi:10.1038/s41588-0190414-y

Mojica, F. J. M., Díez-Villaseñor, C. S., García-Martínez, J. S., and Soria, E. (2005). Intervening Sequences of Regularly Spaced Prokaryotic Repeats Derive from Foreign Genetic Elements. J. Mol. Evol. 60, 174-182. doi:10.1007/s00239-0040046-3

Nakayasu, M., Akiyama, R., Lee, H. J., Osakabe, K., Osakabe, Y., Watanabe, B., et al. (2018). Generation of a-solanine-free Hairy Roots of Potato by CRISPR/Cas9 Mediated Genome Editing of the St16DOX Gene. Plant Physiol. Biochem. 131, 70-77. doi:10.1016/j.plaphy.2018.04.026

Nguyen, H. T., Silva, J. E., Podicheti, R., Macrander, J., Yang, W., Nazarenus, T. J., et al. (2013). Camelina Seed Transcriptome: a Tool for Meal and Oil Improvement and Translational Research. Plant Biotechnol. J. 11, 759-769. doi:10.1111/pbi.12068

Nieves-Cordones, M., Mohamed, S., Tanoi, K., Kobayashi, N. I., Takagi, K., Vernet, A., et al. (2017). Production of low-Cs + rice Plants by Inactivation of the K + Transporter Os HAK 1 with the CRISPR -Cas System. Plant J. 92, 43-56. doi:10.1111/tpj.13632

Nonaka, S., Arai, C., Takayama, M., Matsukura, C., and Ezura, H. (2017). Efficient Increase of $\mathrm{\gamma}$-Aminobutyric Acid (GABA) Content in Tomato Fruits by Targeted Mutagenesis. Sci. Rep. 7, 7057. doi:10.1038/s41598-017-06400-y

O'Keefe, S. F., Wiley, V. A., and Knauft, D. A. (1993). Comparison of Oxidative Stability of High- and normal-oleic Peanut Oils. J. Am. Oil Chem. Soc. 70 (5), 489-492. doi:10.1007/BF02542581

Okuley, J., Lightner, J., Feldmann, K., Yadav, N., Lark, E., and Browse, J. (1994). Arabidopsis FAD2 Gene Encodes the Enzyme that Is Essential for Polyunsaturated Lipid Synthesis. Plant Cell 6, 147-158. doi:10.1105/tpc.6.1.147
Okuzaki, A., Ogawa, T., Koizuka, C., Kaneko, K., Inaba, M., Imamura, J., et al. (2018). CRISPR/Cas9-mediated Genome Editing of the Fatty Acid Desaturase 2 Gene in Brassica Napus. Plant Physiol. Biochem. 131, 63-69. doi:10.1016/ j.plaphy.2018.04.025

Orthwein, A., Fradet-Turcotte, A., Noordermeer, S. M., Canny, M. D., Brun, C. M., Strecker, J., et al. (2014). Mitosis Inhibits DNA Double-Strand Break Repair to Guard against Telomere Fusions. Science 344, 189-193. doi:10.1126/ science. 1248024

Owens, D. D. G., Caulder, A., Frontera, V., Harman, J. R., Allan, A. J., Bucakci, A., et al. (2019). Microhomologies Are Prevalent at Cas9-Induced Larger Deletions. Nucleic Acids Res. 47, 7402-7417. doi:10.1093/nar/gkz459

Peng, F., Zhang, W., Zeng, W., Zhu, J. K., and Miki, D. (2019). Gene Targeting in Arabidopsis via an All-in-one Strategy that Uses a Translational Enhancer to Aid Cas9 Expression. Plant Biotechnol. J. 18, 892-894. doi:10.1111/pbi.13265

Puchta, H. (2005). The Repair of Double-Strand Breaks in Plants: Mechanisms and Consequences for Genome Evolution. J. Exp. Bot. 56, 1-14. doi:10.1093/jxb/ eri025

Qin, R., Li, J., Liu, X., Xu, R., Yang, J., and Wei, P. (20202020). SpCas9-NG SelfTargets the sgRNA Sequence in Plant Genome Editing. Nat. Plants 6, 197-201. doi:10.1038/s41477-020-0603-9

Raboy, V. (2009). Approaches and Challenges to Engineering Seed Phytate and Total Phosphorus. Plant Sci. 177, 281-296. doi:10.1016/j.plantsci.2009.06.012

Raffan, S., Sparks, C., Huttly, A., Hyde, L., Martignago, D., Mead, A., et al. (2021). Wheat with Greatly Reduced Accumulation of Free Asparagine in the Grain, Produced by CRISPR/Cas9 Editing of Asparagine Synthetase Gene TaASN2. Plant Biotechnol. J. 19, 1602-1613. doi:10.1111/pbi.13573

Reis, R. S., Deforges, J., Sokoloff, T., and Poirier, Y. (2020). Modulation of Shoot Phosphate Level and Growth by PHOSPHATE1 Upstream Open Reading Frame. Plant Physiol. 183, 1145-1156. doi:10.1104/pp.19.01549

Ren, J., Meng, X., Hu, F., Liu, Q., Cao, Y., Li, H., et al. (2021). Expanding the Scope of Genome Editing with SpG and SpRY Variants in rice. Sci. China Life Sci. 64, 1784-1787. doi:10.1007/s11427-020-1883-5

Robinson, R. W., and Tomes, M. L. (1968). Ripening Inhibitor: a Gene with Multiple Effects on Ripening. Tomato Genet. Coop. Rep. 18, 36-37.

Rodríguez-Leal, D., Lemmon, Z. H., Man, J., Bartlett, M. E., and Lippman, Z. B. (2017). Engineering Quantitative Trait Variation for Crop Improvement by Genome Editing. Cell 171, 470-480.e8. doi:10.1016/j.cell.2017.08.030

Sánchez-León, S., Gil-Humanes, J., Ozuna, C. V., Giménez, M. J., Sousa, C., Voytas, D. F., et al. (2018). Low-gluten, Nontransgenic Wheat Engineered with CRISPR/Cas9. Plant Biotechnol. J. 16, 902-910. doi:10.1111/pbi.12837

Sasaki, A., Yamaji, N., Yokosho, K., and Ma, J. F. (2012). Nramp5 Is a Major Transporter Responsible for Manganese and Cadmium Uptake in rice. Plant Cell 24, 2155-2167. doi:10.1105/tpc.112.096925

Sashidhar, N., Harloff, H. J., Potgieter, L., and Jung, C. (2020). Gene Editing of Three BnITPK Genes in Tetraploid Oilseed Rape Leads to Significant Reduction of Phytic Acid in Seeds. Plant Biotechnol. J. 18, 2241-2250. doi:10.1111/ pbi. 13380

Scherzer, S., Böhm, J., Krol, E., Shabala, L., Kreuzer, I., Larisch, C., et al. (2015). Calcium Sensor Kinase Activates Potassium Uptake Systems in Gland Cells of Venus Flytraps. Proc. Natl. Acad. Sci. USA 112, 7309-7314. doi:10.1073/ pnas. 1507810112

Sharma, R., Cockram, J., Gardner, K., Russell, J., Ramasay, L., Thomas, W., et al. (2020). Trends of Genetic Changes Uncovered by Env- and Eigen-GWAS in Wheat and Barley. bioRxiv. doi:10.1101/2020.11.27.400333

Shen, L., Hua, Y., Fu, Y., Li, J., Liu, Q., Jiao, X., et al. (2017). Rapid Generation of Genetic Diversity by Multiplex CRISPR/Cas9 Genome Editing in rice. Sci. China Life Sci. 60, 506-515. doi:10.1007/s11427-017-9008-8

Shi, J., Gao, H., Wang, H., Lafitte, H. R., Archibald, R. L., Yang, M., et al. (2017). ARGOS8 Variants Generated by CRISPR-Cas9 Improve maize Grain Yield under Field Drought Stress Conditions. Plant Biotechnol. J. 15, 207-216. doi:10.1111/pbi.12603

Shimada, T., Otani, M., Hamada, T., and Kim, S.-H. (2006). Increase of Amylose Content of Sweetpotato Starch by RNA Interference of the Starch Branching Enzyme II Gene (IbSBEII). Plant Biotechnol. 23, 85-90. doi:10.5511/ plantbiotechnology.23.85

Sivaraman, I., Arumugam, N., Sodhi, Y. S., Gupta, V., Mukhopadhyay, A., Pradhan, A. K., et al. (2004). Development of High Oleic and Low Linoleic Acid Transgenics in a Zero Erucic Acid Brassica Juncea L. (Indian Mustard) Line 
by Antisense Suppression of the Fad2 Gene. Mol. Breed. 13, 365-375. doi:10.1023/B:MOLB.0000034092.47934.d6

Sonnewald, U., and Kossmann, J. (2013). Starches-from Current Models to Genetic Engineering. Plant Biotechnol. J. 11, 223-232. doi:10.1111/pbi.12029

Sugano, S., Hirose, A., Kanazashi, Y., Adachi, K., Hibara, M., Itoh, T., et al. (2020). Simultaneous Induction of Mutant Alleles of Two Allergenic Genes in Soybean by Using Site-Directed Mutagenesis. BMC Plant Biol. 20, 513. doi:10.1186/ s12870-020-02708-6

Sun, Y., Jiao, G., Liu, Z., Zhang, X., Li, J., Guo, X., et al. (2017). Generation of HighAmylose Rice through CRISPR/Cas9-Mediated Targeted Mutagenesis of Starch Branching Enzymes. Front. Plant Sci. 8, 298. doi:10.3389/fpls.2017.00298

Sun, Y., Zhang, X., Wu, C., He, Y., Ma, Y., Hou, H., et al. (2016). Engineering Herbicide-Resistant rice Plants through CRISPR/Cas9-mediated Homologous Recombination of Acetolactate Synthase. Mol. Plant 9, 628-631. doi:10.1016/ j.molp.2016.01.001

Svitashev, S., Young, J. K., Schwartz, C., Gao, H., Falco, S. C., and Cigan, A. M. (2015). Targeted Mutagenesis, Precise Gene Editing, and Site-Specific Gene Insertion in Maize Using Cas9 and Guide RNA. Plant Physiol. 169, 931-945. doi:10.1104/pp.15.00793

Sweeney, M. T., Thomson, M. J., Pfeil, B. E., and McCouch, S. (2006). Caught RedHanded:RcEncodes a Basic Helix-Loop-Helix Protein Conditioning Red Pericarp in Rice. Plant Cell 18, 283-294. doi:10.1105/tpc.105.038430

Tan, J., Zhao, Y., Wang, B., Hao, Y., Wang, Y., Li, Y., et al. (2020). Efficient CRISPR/ Cas9-based Plant Genomic Fragment Deletions by Microhomology-mediated End Joining. Plant Biotechnol. J. 18, 2161-2163. doi:10.1111/pbi.13390

Tang, L., Mao, B., Li, Y., Lv, Q., Zhang, L., Chen, C., et al. (2017). Knockout of OsNramp5 Using the CRISPR/Cas9 System Produces Low Cd-Accumulating Indica rice without Compromising Yield. Sci. Rep. 7, 14438. doi:10.1038/ s41598-017-14832-9

Tang, Y., Abdelrahman, M., Li, J., Wang, F., Ji, Z., Qi, H., et al. (2021). CRISPR/ Cas9 Induces Exon Skipping that Facilitates Development of Fragrant rice. Plant Biotechnol. J. 19, 642-644. doi:10.1111/pbi.13514

Terés, S., Barcelo-Coblijn, G., Benet, M., Alvarez, R., Bressani, R., Halver, J. E., et al. (2008). Oleic Acid Content Is Responsible for the Reduction in Blood Pressure Induced by Olive Oil. Proc. Natl. Acad. Sci. 105, 13811-13816. doi:10.1073/ pnas. 0807500105

Thompson, A. J., Tor, M., Barry, C. S., Vrebalov, J., Orfila, C., Jarvis, M. C., et al. (1999). Molecular and Genetic Characterization of a Novel Pleiotropic TomatoRipening Mutant1. Plant Physiol. 120, 383-390. doi:10.1104/pp.120.2.383

Tigchelaar, E. C. M., Tomes, M. L., Kerr, E. A., and Barman, R. J. (1973). A New Fruit Ripening Mutant, Non-ripening (Nor). Tomato Genet. Coop. Rep. 23, 33.

Truong, L. N., Li, Y., Shi, L. Z., Hwang, P. Y.-H., He, J., Wang, H., et al. (2013). Microhomology-mediated End Joining and Homologous Recombination Share the Initial End Resection Step to Repair DNA Double-Strand Breaks in Mammalian Cells. Proc. Natl. Acad. Sci. 110, 7720-7725. doi:10.1073/ pnas. 1213431110

Tsuda, T. (2012). Dietary Anthocyanin-Rich Plants: Biochemical Basis and Recent Progress in Health Benefits Studies. Mol. Nutr. Food Res. 56, 159-170. doi:10.1002/mnfr.201100526

Tuladhar, R., Yeu, Y., Tyler Piazza, J., Tan, Z., Rene Clemenceau, J., Wu, X., et al. (2019). CRISPR-Cas9-based Mutagenesis Frequently Provokes On-Target mRNA Misregulation. Nat. Commun. 10, 4056. doi:10.1038/s41467-01912028-5

Uluisik, S., Chapman, N. H., Smith, R., Poole, M., Adams, G., Gillis, R. B., et al. (2016). Genetic Improvement of Tomato by Targeted Control of Fruit Softening. Nat. Biotechnol. 34, 950-952. doi:10.1038/nbt.3602

Véry, A.-A., Nieves-Cordones, M., Daly, M., Khan, I., Fizames, C., and Sentenac, H. (2014). Molecular Biology of K+ Transport across the Plant Cell Membrane: what Do We Learn from Comparison between Plant Species? J. Plant Physiol. 171, 748-769. doi:10.1016/j.jplph.2014.01.011

Vinayagam, R., and Xu, B. (2015). Antidiabetic Properties of Dietary Flavonoids: a Cellular Mechanism Review. Nutr. Metab. (Lond) 12, 60. doi:10.1186/s12986015-0057-7

Vongvanrungruang, A., Mongkolsiriwatana, C., Boonkaew, T., Sawatdichaikul, O., Srikulnath, K., and Peyachoknagul, S. (2016). Single Base Substitution Causing the Fragrant Phenotype and Development of a Type-specific Marker in Aromatic Coconut (Cocos Nucifera). Genet. Mol. Res. 15, gmr.15038748. doi:10.4238/gmr.15038748
Wallace, T., Slavin, M., and Frankenfeld, C. (2016). Systematic Review of Anthocyanins and Markers of Cardiovascular Disease. Nutrients 8, 32. doi: $10.3390 /$ nu 8010032

Waltz, E. (2016). Gene-edited CRISPR Mushroom Escapes US Regulation. Nature 532, 293. doi:10.1038/nature.2016.19754

Wang, C., Shen, L., Fu, Y., Yan, C., and Wang, K. (2015). A Simple CRISPR/Cas9 System for Multiplex Genome Editing in Rice. J. Genet. Genomics 42, 703-706. doi:10.1016/j.jgg.2015.09.011

Wang, D., Samsulrizal, N., Yan, C., Allcock, N. S., Craigon, J., Blanco-Ulate, B., et al. (2019a). Characterisation of CRISPR Mutants Targeting Genes Modulating Pectin Degradation in Ripening Tomato. Plant Physiol. 179, pp.01187.2018-557. doi:10.1104/pp.18.01187

Wang, G.-D., Xie, H.-B., Peng, M.-S., Irwin, D., and Zhang, Y.-P. (2014). Domestication Genomics: Evidence from Animals. Annu. Rev. Anim. Biosci. 2, 65-84. doi:10.1146/annurev-animal-022513-114129

Wang, J., Meng, X., Hu, X., Sun, T., Li, J., Wang, K., et al. (2019b). xC As9 Expands the Scope of Genome Editing with Reduced Efficiency in rice. Plant Biotechnol. J. 17, 709-711. doi:10.1111/pbi.13053

Wang, L.-S., and Stoner, G. D. (2008). Anthocyanins and Their Role in Cancer Prevention. Cancer Lett. 269, 281-290. doi:10.1016/j.canlet.2008.05.020

Wang, M., Lu, Y., Botella, J. R., Mao, Y., Hua, K., and Zhu, J.-k. (2017). Gene Targeting by Homology-Directed Repair in Rice Using a Geminivirus-Based CRISPR/Cas9 System. Mol. Plant 10, 1007-1010. doi:10.1016/ j.molp.2017.03.002

Wang, P., Zhao, F.-J., and Kopittke, P. M. (2019c). Engineering Crops without Genome Integration Using Nanotechnology. Trends Plant Sci. 24, 574-577. doi:10.1016/j.tplants.2019.05.004

Wang, S., Yang, Y., Guo, M., Zhong, C., Yan, C., and Sun, S. (2020). Targeted Mutagenesis of Amino Acid Transporter Genes for rice Quality Improvement Using the CRISPR/Cas9 System. Crop J. 8, 457-464. doi:10.1016/ j.cj.2020.02.005

Wang, Y., Liu, X., Zheng, X., Wang, W., Yin, X., Liu, H., et al. (2021). Creation of Aromatic maize by CRISPR/Cas. J. Integr. Plant Biol. 63, 1664-1670. doi:10.1111/jipb.13105

Woo, J. W., Kim, J., Kwon, S. I., Corvalán, C., Cho, S. W., Kim, H., et al. (2015). DNA-free Genome Editing in Plants with Preassembled CRISPR-Cas9 Ribonucleoproteins. Nat. Biotechnol. 33 (11), 1162-1164. doi:10.1038/nbt.3389

Wood, C. C., Okada, S., Taylor, M. C., Menon, A., Mathew, A., Cullerne, D., et al. (2018). Seed-specific RNAi in Safflower Generates a Superhigh Oleic Oil with Extended Oxidative Stability. Plant Biotechnol. J. 16, 1788-1796. doi:10.1111/ pbi. 12915

Xie, X., Ma, X., Zhu, Q., Zeng, D., Li, G., and Liu, Y.-G. (2017). CRISPR-GE: A Convenient Software Toolkit for CRISPR-Based Genome Editing. Mol. Plant 10, 1246-1249. doi:10.1016/j.molp.2017.06.004

Xu, G., Yuan, M., Ai, C., Liu, L., Zhuang, E., Karapetyan, S., et al. (2017). uORFmediated Translation Allows Engineered Plant Disease Resistance without Fitness Costs. Nature 545, 491-494. doi:10.1038/nature22372

Xu, J., Kang, B. C., Naing, A. H., Bae, S. J., Kim, J. S., Kim, H., et al. (2020). CRISPR/ Cas9-mediated Editing of 1-aminocyclopropane-1-carboxylate Oxidase1 Enhances Petunia Flower Longevity. Plant Biotechnol. J. 18, 287-297. doi:10.1111/pbi.13197

Xu, Y., Lin, Q., Li, X., Wang, F., Chen, Z., Wang, J., et al. (2021a). Fine-tuning the Amylose Content of rice by Precise Base Editing of the Wx Gene. Plant Biotechnol. J. 19, 11-13. doi:10.1111/pbi.13433

Xu, Z.-S., Yang, Q.-Q., Feng, K., and Xiong, A.-S. (2019). Changing Carrot Color: Insertions in DcMYB7 Alter the Regulation of Anthocyanin Biosynthesis and Modification. Plant Physiol. 181, 195-207. doi:10.1104/pp.19.00523

Xu, Z., Kuang, Y., Ren, B., Yan, D., Yan, F., Spetz, C., et al. (2021b). SpRY Greatly Expands the Genome Editing Scope in rice with Highly Flexible PAM Recognition. Genome Biol. 22, 6. doi:10.1186/s13059-020-02231-9

Yang, S. F., and Hoffman, N. E. (1984). Ethylene Biosynthesis and its Regulation in Higher Plants. Annu. Rev. Plant Physiol. 35, 155-189. doi:10.1146/ annurev.pp.35.060184.001103

Yang, T., Deng, L., Zhao, W., Zhang, R., Jiang, H., Ye, Z., et al. (2019a). Rapid Breeding of Pink-Fruited Tomato Hybrids Using the CRISPR/Cas9 System. J. Genet. Genomics 46, 505-508. doi:10.1016/j.jgg.2019.10.002

Yang, Y., Guo, M., Li, R., Shen, L., Wang, W., Liu, M., et al. (2015). Identification of Quantitative Trait Loci Responsible for rice Grain Protein Content Using 
Chromosome Segment Substitution Lines and fine Mapping of $q P C-1$ in rice (Oryza Sativa L.). Mol. Breed. 35, 130. doi:10.1007/s11032-015-0328-Z

Yang, Y., Guo, M., Sun, S., Zou, Y., Yin, S., Liu, Y., et al. (2019b). Natural Variation of OsGluA2 Is Involved in Grain Protein Content Regulation in rice. Nat. Commun. 10, 1949. doi:10.1038/s41467-019-09919-y

Yang, Y., Shen, Z., Xu, C., Guo, M., Li, Y., Zhang, Y., et al. (2020). Genetic Improvement of Panicle-Erectness Japonica rice toward Both Yield and Eating and Cooking Quality. Mol. Breed. 40, 5. doi:10.1007/s11032-020-01127-7

Yasunari, T. J., Stohl, A., Hayano, R. S., Burkhart, J. F., Eckhardt, S., and Yasunari, T. (2011). Cesium-137 Deposition and Contamination of Japanese Soils Due to the Fukushima Nuclear Accident. Proc. Natl. Acad. Sci. 108, 19530-19534. doi:10.1073/pnas.1112058108

Yin, K., Gao, C., and Qiu, J.-L. (2017). Progress and Prospects in Plant Genome Editing. Nat. Plants 3, 17107. doi:10.1038/nplants.2017.107

Yu, Q.-h., Wang, B., Li, N., Tang, Y., Yang, S., Yang, T., et al. (2017). CRISPR/Cas9induced Targeted Mutagenesis and Gene Replacement to Generate Long-Shelf Life Tomato Lines. Sci. Rep. 7, 11874. doi:10.1038/s41598-017-12262-1

Yundaeng, C., Somta, P., Tangphatsornruang, S., Chankaew, S., and Srinives, P. (2015). A Single Base Substitution in BADH/AMADH Is Responsible for Fragrance in Cucumber (Cucumis Sativus L.), and Development of SNAP Markers for the Fragrance. Theor. Appl. Genet. 128, 1881-1892. doi:10.1007/ s00122-015-2554-5

Yundaeng, C., Somta, P., Tangphatsornruang, S., Wongpornchai, S., and Srinives, P. (2013). Gene Discovery and Functional Marker Development for Fragrance in Sorghum (Sorghum Bicolor (L.) Moench). Theor. Appl. Genet. 126, 2897-2906. doi:10.1007/s00122-013-2180-z

Zeng, D., Li, X., Huang, J., Li, Y., Cai, S., Yu, W., et al. (2020a). Engineered Cas9 Variant Tools Expand Targeting Scope of Genome and Base Editing in rice. Plant Biotechnol. J. 18, 1348-1350. doi:10.1111/pbi.13293

Zeng, D., Liu, T., Ma, X., Wang, B., Zheng, Z., Zhang, Y., et al. (2020b). Quantitative Regulation of Waxy Expression by CRISPR/Cas9-based Promoter and 5'UTRintron Editing Improves Grain Quality in rice. Plant Biotechnol. J. 18, 2385-2387. doi:10.1111/pbi.13427

Zhai, Y., Yu, K., Cai, S., Hu, L., Amoo, O., Xu, L., et al. (2020). Targeted Mutagenesis of BnTT8 Homologs Controls Yellow Seed Coat Development for Effective Oil Production in Brassica Napus L. Plant Biotechnol. J. 18, 1153-1168. doi:10.1111/pbi.13281

Zhang, C., Wang, Y., Wang, F., Zhao, S., Song, J., Feng, F., et al. (2021). Expanding Base Editing Scope to Near-PAMless with Engineered CRISPR/Cas9 Variants in Plants. Mol. Plant 14, 191-194. doi:10.1016/j.molp.2020.12.016

Zhang, H., Demirer, G. S., Zhang, H., Ye, T., Goh, N. S., Aditham, A. J., et al. (2019). DNA Nanostructures Coordinate Gene Silencing in Mature Plants. Proc. Natl. Acad. Sci. USA 116, 7543-7548. doi:10.1073/pnas.1818290116
Zhang, H., Si, X., Ji, X., Fan, R., Liu, J., Chen, K., et al. (2018). Genome Editing of Upstream Open reading Frames Enables Translational Control in Plants. Nat. Biotechnol. 36, 894-898. doi:10.1038/nbt.4202

Zhang, J., Zhang, H., Botella, J. R., and Zhu, J.-K. (2017). Generation of New Glutinous rice by CRISPR/Cas9-targeted Mutagenesis of the Waxy Gene in Elite rice Varieties. J. Integr. Plant Biol. 60, 369-375. doi:10.1111/ jipb. 12620

Zhang, T., Wu, A., Yue, Y., and Zhao, Y. (2020). uORFs: Important Cis-Regulatory Elements in Plants. Ijms 21, 6238. doi:10.3390/ijms21176238

Zhang, Z., Belcram, H., Gornicki, P., Charles, M., Just, J., Huneau, C., et al. (2011). Duplication and Partitioning in Evolution and Function of Homoeologous $Q$ Loci Governing Domestication Characters in Polyploid Wheat. Proc. Natl. Acad. Sci. 108, 18737-18742. doi:10.1073/pnas.1110552108

Zhong, Y., Blennow, A., Kofoed-Enevoldsen, O., Jiang, D., and Hebelstrup, K. H. (2018). Protein Targeting to Starch 1 Is Essential for Starchy Endosperm Development in Barley. J. Exp. Bot. 70, 485-496. doi:10.1093/jxb/ery398

Zhong, Z., Sretenovic, S., Ren, Q., Yang, L., Bao, Y., Qi, C., et al. (2019). Improving Plant Genome Editing with High-Fidelity xCas9 and Noncanonical PAM-Targeting Cas9-NG. Mol. Plant 12, 1027-1036. doi:10.1016/j.molp.2019.03.011

Zhu, L., Gu, M., Meng, X., Cheung, S. C. K., Yu, H., Huang, J., et al. (2012). Highamylose rice Improves Indices of Animal Health in normal and Diabetic Rats. Plant Biotechnol. J. 10, 353-362. doi:10.1111/j.1467-7652.2011.00667.x

Zhu, Y., Lin, Y., Chen, S., Liu, H., Chen, Z., Fan, M., et al. (2019). CRISPR/Cas9mediated Functional Recovery of the Recessive Rc Allele to Develop Red rice. Plant Biotechnol. J. 17, 2096-2105. doi:10.1111/pbi.13125

Conflict of Interest: The authors declare that the research was conducted in the absence of any commercial or financial relationships that could be construed as a potential conflict of interest.

Publisher's Note: All claims expressed in this article are solely those of the authors and do not necessarily represent those of their affiliated organizations, or those of the publisher, the editors and the reviewers. Any product that may be evaluated in this article, or claim that may be made by its manufacturer, is not guaranteed or endorsed by the publisher.

Copyright $\odot 2022$ Yang, Xu, Shen and Yan. This is an open-access article distributed under the terms of the Creative Commons Attribution License (CC BY). The use, distribution or reproduction in other forums is permitted, provided the original author(s) and the copyright owner(s) are credited and that the original publication in this journal is cited, in accordance with accepted academic practice. No use, distribution or reproduction is permitted which does not comply with these terms. 